\title{
TRANSFER OF INSTRUCTIONAL PRACTICES FROM FREEDOM SCHOOLS TO THE CLASSROOM
}

Myah D. Stanford

\author{
Dissertation Prepared for the Degree of \\ DOCTOR OF PHILOSOPHY
}

\author{
University of North Texas
}

May 2016

APPROVED:

Jeanne Tunks, Major Professor Ricardo Gonzalez-Carriedo, Committee Member Miriam Ezzani, Committee Member Tambra Jackson, Committee Member James Laney, Department Chair Jerry Thomas, Dean 
Stanford, Myah D. Transfer of instructional practices from Freedom Schools to the classroom. Doctor of Philosophy (Curriculum and Instruction), May 2016, 104 pp., 2 tables, references, 67 titles.

The instructional practices of three current classroom teachers who formerly served as Servant Leader Interns (SLIs) in the Children's Defense Fund Freedom Schools (CDFFS) Program were examined. Haskell (2001) outlined eleven principles of transfer of learning, which were used to survey the levels of transfer established from service in Freedom Schools to practice in the traditional classroom. Individual surveys, The Freedom School Pedagogies Teacher Observation Record (FSPTOR) along with interviews of each participant were used for data collection; all three components were used to triangulate the findings. The findings from this study verified that low transfer was observed when the minimal application of the principles of learning was applied. This study revealed that for transfer to occur at high levels, it is imperative that adherence to all 11 principals is made, and the understanding of transfer, the application of transfer, and reflection on transfer are implemented. If the transfer of instructional practices is a goal of CDFFS for SLIs, the CDFFS program should consider implementing transfer of learning theory in future SLI training. 
Copyright 2016

by

Myah D. Stanford 


\section{ACKNOWLEDGEMENTS}

To my Lord and Savior Jesus Christ, I thank you for your abundant faithfulness and mercy. Thank you for planting this seed in me and seeing it to fruition. To my loving and supportive parents, thank you for helping me to reach the stars! You two have encouraged me to go above and beyond the status quo while supporting me and being my biggest cheerleaders. Words cannot express my gratitude. A huge thank you to my siblings, entire family, and friends.Your constant words of encouragement, prayers, and positive thoughts were felt and appreciated. A special thank you to my committee. I was blessed to be surrounded by a group of scholars who have pushed me and supported me throughout the journey. Dr. Tunks, thank you for being a mentor, advisor, and friend. I am grateful that you took me on as a graduate student. Dr. Jackson, thank you for being a mentor, a sister, and inspiration over the years. Dr. Ezzani, thank you for always bringing insight. my studies through different Dr. Gonzalez-Carriedo, you have definitely pushed me to be a better researcher and student. I thank each of you from the bottom of my heart. To my ancestors who sacrificed and fought so that I may be able to receive an education. I pray that I am rising to your standards as I follow in your footsteps. Additionally, I pray that I too am leaving a trail of footsteps for younger generations. To my Children's Defense Fund Freedom Schools family, I love, respect, and appreciate you all! Joining the Freedom Schools family in November 2005, changed me forever. Because of Freedom Schools, I know that there is Something Inside So Strong. I dedicate this work in loving memory of my grandmother Lillie Pearl Adams. You transitioned to your heavenly mansion a few months shy of the completion of this dissertation. However, I feel your spirit all around me. I know that you are in heaven smiling on me with such pride and joy.

It takes a village......thank you to those who make up mine! 


\section{TABLE OF CONTENTS}



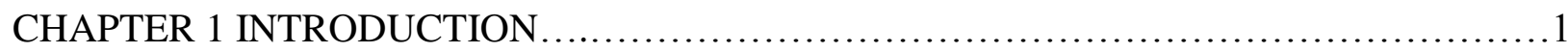

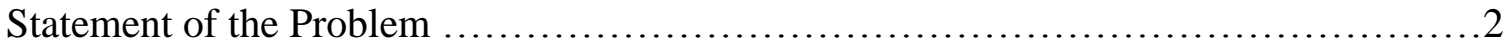

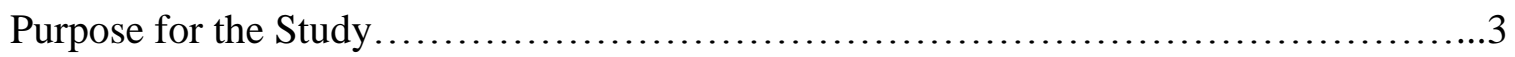

Research Questions..........................................................

Theoretical Framework ......................................................

Transfer of Learning...................................................

Levels of Transfer......................................................

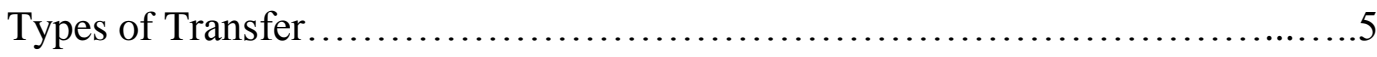

Principles............................................................6

Assumptions............................................................11

Definition of Terms..................................................... 15

Significance........................................................... 17

Limitations of Study.................................................. 17

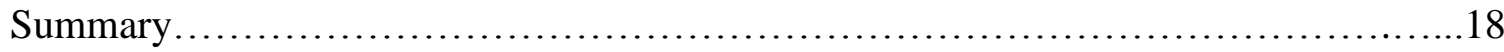

CHAPTER 2 RELATED LITERATURE............................................ 19

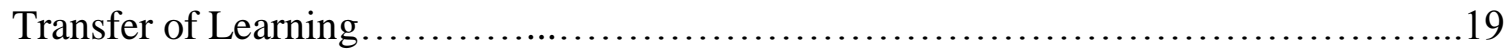

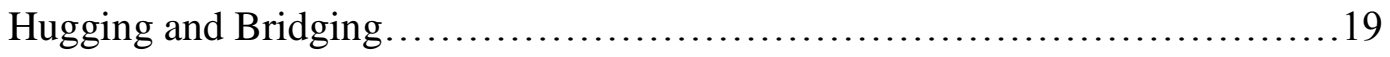

Culture and Transfer................................................21

Freedom Schools..........................................................22

Historical Development.............................................22




Present Day Freedom Schools............................................... 24

Inclusiveness...............................................25

Cultural Relevancy and Responsiveness........................................27

Teacher Support...................................................28

District and School Culture.............................................29

Student's Response to Culturally Relevant Pedagogy..........................31

Culturally Relevant Pedagogy and the Integrated Reading Curriculum...........31

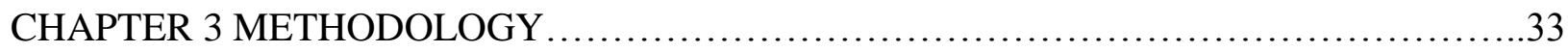

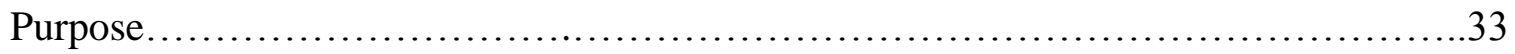

Research Questions...................................................... 33

Research Design..........................................................33

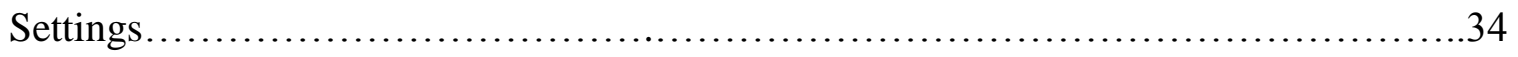

Participants...............................................................



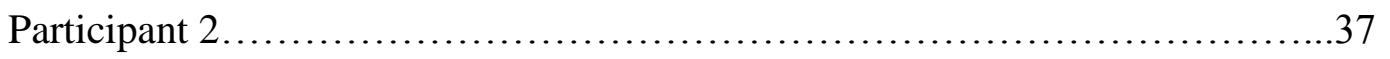

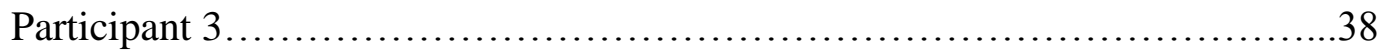

Data Sources and Collecting...............................................40

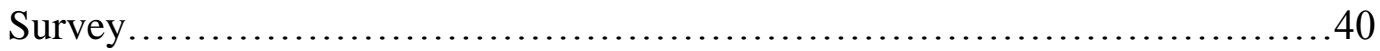

Observations.....................................................41

Interviews ....................................................... 41

Data Collection Timeline..................................................42

Data Analysis.......................................................... 42

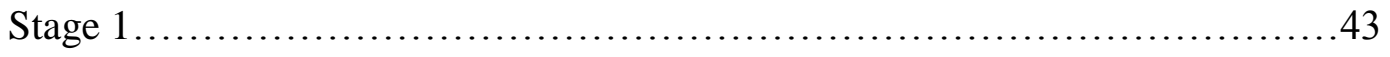






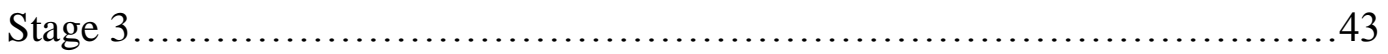



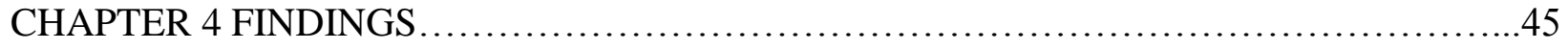

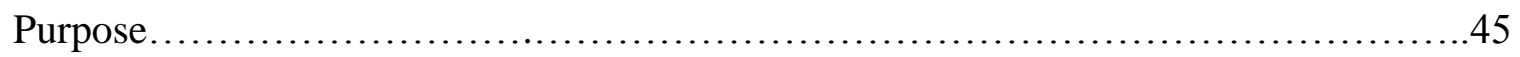

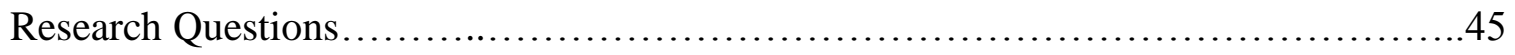

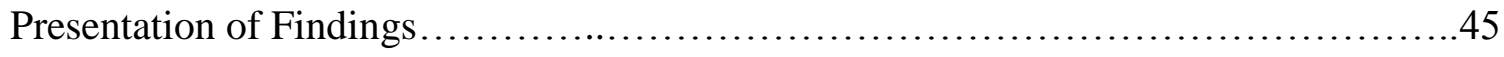

Participant 1 Jacob.....................................................46

Participant 2 Faith....................................................... 51

Participant 3 Janet......................................................5

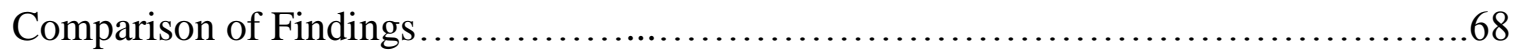

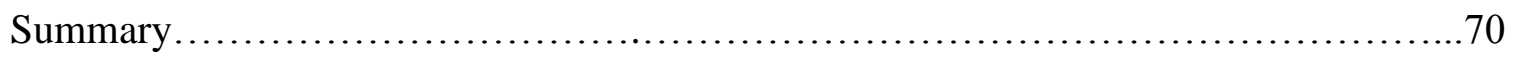

CHAPTER 5 IMPLICATIONS ..........................................................

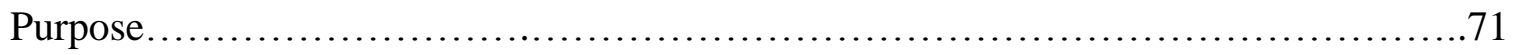

Research Questions........................................................... 71

Transfer of Learning Assumptions................................................71

Implications for Future Research................................................ 81



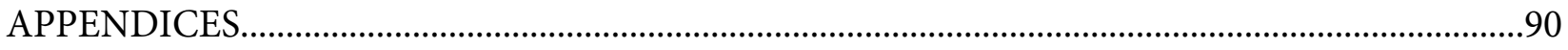

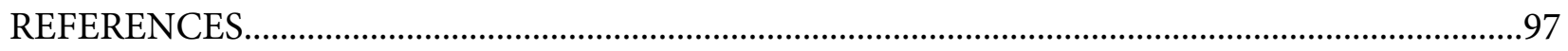




\section{CHAPTER 1}

\section{THEORETICAL FOUNDATIONS}

\section{Introduction}

All learning builds on previous knowledge with the purpose of transferring the knowledge from one area to another (Halpern and Hakel, 2003). Haskell (2001) expands on this idea by calling this exchange of knowledge transfer of learning. He concludes that in order for learning to transfer, we must understand how to apply what we have learned in the past in order to understand and grasp the future. Although these suggestions of transfer of learning seem simple and straightforward, yet transfer of learning from one domain to another is an extensive and complicated process. Haskell describes a process that involves levels and types of transfer and has 11 principles that determine whether transfer has occurred. The ability of a novice teacher to transfer the learning gained in a teacher preparation program to a classroom is a complex process.

Teacher preparation programs, tasked with preparing individuals to enter the teaching profession, accept responsibility to prepare teachers to teach a diverse community of students, particularly students of color (Ladson-Billings, 1999). However, the amount of transfer between teacher preparation programs and classroom teaching is sparsely documented. The teacher plays a major part in the education of students. Their demeanor, relationship, and pedagogy greatly influence the success or lack of success of their students. This is especially seen in low-income schools where many students are not in the position to receive extra academic help outside of school (Delpit, 2012). In these schools, the necessity of a high performing and competent teacher is crucial. 
In 1963, the Student Non-Violent Coordinating Committee (SNCC) released a report on the state of Southern Schools. The report shed light on the failure of southern states in regards to children of color (Perlstein, 1990). The report became the impetus for the first Freedom Schools which took place during the 1964 Freedom Summer in the Mississippi Delta. During that summer, over 2,000 middle and high school students participated in the Mississippi Freedom Schools (Hale, 2011). The Mississippi Freedom Schools program served as an educational supplement for Black students who attended schools in impoverished and rural areas. The program sought to not only fill in the educational gaps, but to offer these students a wider educational experience that they could share with others in their schools (Ligon \& Chilcoat, 1999). The 1964 Freedom Summer spearheaded the creation of present-day Freedom Schools.

Like the 1964 Freedom Schools, present day Freedom Schools seeks to close the achievement gap between children of color and their counterparts through curbing summer learning loss through literature, empowerment, and community. The current Freedom Schools program strives to make children fall in love with reading and to become active citizens in their community.

It is unclear whether teachers who have served in the present-day CDFFS program take the Freedom Schools model into the traditional school settings with yearlong curriculum. Specifically, whether these teaching strategies and instructional practices from the summer model transfer, and on what level or type of transfer it occurs. Using Transfer of Learning as a theoretical framework, this study examined the transfer of instructional practices from the CDFFS program into traditional classrooms. 


\section{Statement of the Problem}

The CDFFS program is an intensive, six-week summer literacy enrichment program. The program offers unique training for those who serve as the instructional leaders within the program. The CDFFS program offers a Culturally Relevant training of instructional practices to the SLIs in the program. However, there is no evidence of whether the Freedom Schools'

pedagogies and instructional practices taught and used by SLIs in the Freedom Schools program are transferred and applied by current classroom teachers who formerly participated as SLIs in the Freedom Schools.

\section{Purpose for Study}

The purpose of this study was to investigate the transfer of instructional practices from the CDFFS program to the regular classroom by teachers who served as servant leader interns (SLIs) in the Freedom Schools program.

\section{Research Questions}

1. What levels of Freedom Schools instructional practices are transferred into traditional classrooms, as observed among former Freedom Schools Servant Leader Interns (SLIs) who are current classroom teachers?

2. What practices gleaned from SLI experiences do K-12 teachers, who served as SLIs, name as influential experiences in their teaching practice?

3. What evidence is there that specific types of transfer occur through the Freedom Schools practices in use in the current classrooms of SLIs? 


\section{Theoretical Framework}

Transfer of Learning

Robert Haskell (2001) describes in detail the transfer of learning theory. He defines transfer as "applying what we have learned in the past to understanding and grasping the present" (p.75). In short, all learning builds on previous experiences. Therefore, in order to learn something new, the learner must build on what they already know. Haskell begins the discussion of transfer of learning with the following quote from Jerome Bruner (1973):

Learning often cannot be translated into a generic form until there has been enough mastery of the specifics of the situation to permit the discovery of lower order regularities which can then be recombined into high-order, more generic coding systems. (p.232) Using this as a basis for his theory of transfer, Haskell created a taxonomy that includes levels, types, and principles. The levels indicate the nearness and distance of transfer from the original experience. The types indicate the relationship between the knowledge gained and transfer mechanism. The principles define the assumptions that when met, foster transfer. Levels of transfer

Nonspecific transfer. The first level, nonspecific transfer, is the basis of transfer. It describes all learning in transfer due to its connection to a past experience or prior knowledge. Haskell describes this as a "trivial" but "necessary" level of transfer. This level is the building blocks for all transfer of learning.

Application transfer. Application, the second level, requires one to use what was previously learned for a current and specific situation. An example is the goal of teachers being able to revert back to the theoretical and pedagogical practices learned in teacher preparation programs when faced with a situation in their classrooms. 
Context transfer. Level three, context transfer, describes the transfer of knowledge within a different context. In this level of transfer, a person is able to apply prior knowledge within a different domain from where knowledge was initially gained.

Near transfer. Near transfer, the next level, is similar to context transfer in that it requires one to transfer knowledge to a new context, however, this context is similar to the domain in which the original knowledge was gained. An example is a teacher being able to transfer the knowledge gained in student teaching to their current context as a classroom teacher of their own class.

Far transfer. Far transfer describes the application of knowledge between two unlikely instances. For instance, a teacher who chooses education as a career choice later in life, using their skills and knowledge developed from years of working in an entirely different profession.

Creative transfer. Lastly, development or creative transfer describes the creation of new knowledge based on the transfer of prior knowledge. Haskell describes this level as "The interaction of the newly discovered similarity between the old and the new, a new concept is created" (p.30). According to Haskell, the levels of transfer are subjective. He argues that the first three levels are just applying same knowledge while the latter three require the learner to learn something new therefore achieving true transfer.

Types of transfer

From these six levels of transfer, Haskell derives fourteen individual types of transfer that serve to define how transfer is observed. He also claims that through the identification of these types we can begin to recognize when, how, and where transfer occurs. Within each type are specific identifiers to guide the researcher's understanding of the transfer under examination. Definitions 14 types of transfer are found in Table 1. 
Table 1.1 Haskell's 14 Types of Transfer

\begin{tabular}{ll}
\hline Type & Definition - Identifiers \\
\hline 1. Content to Content & $\begin{array}{l}\text { Making use of what we know in one subject area to the learning } \\
\text { of another area. }\end{array}$
\end{tabular}

2. Procedural to Procedural Using the procedures learned in one skill area in another skill area.

3. Declarative to Procedural When learning about something helps in actually doing something.

4. Procedural to Declarative When practical experience in an area helps us to learn more abstract knowledge of the area.

5.Strategic

When knowledge about out mental processes, such as how we learn or remember, is gained through monitoring our mental activities during learning.

6. Conditional

When knowledge concerning when to apply knowledge learned in one context can be transferred to another context.

7. Theoretical

Understanding deep level relationships of cause and effect in one area that can be transferred to another.

8. General or Nonspecific

When previous knowledge is transferred to another situation where no similarities between the situations exist.

9. Literal

Using knowledge or a procedure directly in a new learning situation.

10. Vertical

Transferring prior learning to new learning in a higher knowledge hierarchy than the prior learning.

11. Lateral

When previous learning is transferred to the same level in a hierarchy.

12. Reverse

When existing knowledge is modified and re-viewed in terms of its similarities to the new information.

13.Propotional

A more abstract transfer between two instances.

14. Relational

Seeing the same structure between two things.

Principles

1. Acquire a large primary knowledge base in the area in which transfer is required. 
Learners must possess a large primary knowledge base in the content area requiring transfer (Haskell, 2001). However, simply possessing a knowledge base is insufficient. In addition to possessing a knowledge base, one must possess thinking and reasoning because transfer requires that learning be transformed into a basic form. One must incorporate a concept or principle "so thoroughly into one's cognitive system that it becomes a part of one's personality" (p.116). A high knowledge base enables individuals to identify problems with great precision and speed by creating an initial interpretation of the problem that enables the expert to engage in the best path to a solution without the need to consider all others. In addition, such a knowledge base permits us to perceive patterns in our environment.

\section{Acquire some level of knowledge base in subjects outside the primary area.}

Haskell argues that in order for adequate transfer to take place, a large knowledge base is required. Conversely, a broad knowledge base alone won't learn transfer, but one must acquire knowledge base in subjects outside of the primary area. He calls this "useless" and "irrelevant" knowledge. He gives the example of two sets of kittens that were trying to learn the task of pulling a string to open the door. One group was exposed to seeing a cat perform the task correctly every time while the other group witnessed a cat struggle with the task before finally getting the door open. Many argue that showing a wrong example is useless information. However in this experiment, the kittens that saw the cat make mistakes were able to transfer their learning more quickly and open the door before the kittens that did not have this exposure. Haskell goes on to give other examples of persons who took the "useless" or "irrelevant" information and transferred it later. Suggesting that it is necessary for one to learn a large amount of outside knowledge in order to have an adequate knowledge base.

\section{Understand what transfer of learning is and how it works.}


Transfer is conducive to all levels of learning, ranging from low-level skills to high-level theoretical thinking therefore; learners must grasp the nature and function of transfer (Haskell, 2001). Since transfer influences all learning, memory, problem solving, and cognitive processes, it is imperative that learners understand what transfer of learning is and how it works. As a process, transfer enables our past knowledge to impact our current learning. For this to occur, transfer requires analogical reasoning, debatably, the fundamental instrument in learning. Transfer, is responsible for our creativity and learning itself.

\section{Understand the history in the area(s) that transfer is wanted.}

Haskell argues that the knowledge of history is the basis of transfer of learning. In order to transfer learning, you must have an understanding of the events that have happened previously. His case for understanding history does not relate to just the knowledge of historical events, but the knowledge of the history of transfer of learning. There are seven models of transfer; formal, identical, general, stimulus generalization, cognitive information processing, metacognition, and instructional. In order to accurately use transfer of learning, one must know which of these models is most appropriate "for certain kinds of transfer material (e.g., technical vs. theory based), for near and far transfer, or for different learning situations" (p.89).

\section{Acquire motivation, or more specifically, a "spirit of transfer".}

Like anything in life, when one has a motivation behind their doing, the results are better. The same is said for transfer of learning. Haskell describes the role that emotions have on learning. He doesn't refer to this emotion as motivation, but as "spirit"; more precisely, the "spirit of transfer". He states, "the transfer of spirit is a psychological, emotional, and motivational disposition toward deep learning" (p.117). Haskell gives the example of Sir Isaac Newton, who was motivated out of deep religious conviction to develop the perfect law. The "spirit of 
transfer" represents the passion that one has for what they do, be it research, learning, or teaching, when one is passionate, that passion stems from them and produces greater results. 6. Develop an orientation to think and encode learning in transfer terms.

All learning takes place in a particular context. The context in which learning takes place, determines whether one will be able to transfer that knowledge when necessary. Haskell argues the "largest breach of context concerns learning in the classroom versus the everyday world" (p.140); this is one of the major failures of K-12 education. Oftentimes, students are not able to transfer the knowledge learned in the classroom to everyday experiences. Prompting one to ask, is the knowledge actually valuable? Students must learn to encode this knowledge so that it may be transferred when needed.

\section{Create cultures of transfer or support systems.}

Transferring knowledge does not always come natural for students. They must be surrounded by a culture that supports transfer. This culture is one that acknowledges transfer and supports it throughout the learning process. Haskell suggests that those who receive on the job training have built-in culture of transfer and a support system. He states that these cultures thrive in transfer because

Learning is (a) a valued goal (i.e., the job), (b) it is meaningfully evaluated (i.e., job performance), (c) it is rewarded, (d) it is a paycheck, (e) it is action based (i.e., application activities), and (f) it involves social interaction with other workers around common and related work activities (p. 147).

Like the cultures developed within workplaces, this similar culture must be built within institutions of learning in order for successful and long-term transfer to take place. 
8.Understand the theory underlying the area(s) in which we want to see transfer.

Haskell discusses the need for one to understand the theory that underlies the area in which they want to see the transfer. Haskell states that the eyes of "students-and even many faculty...glaze over" (p.153) when theory enters into a discussion. However, he argues that theories are a part of our everyday lives. In fact, much of our theoretical beliefs are engrained in and are a part of our unconsciousness. Haskell points out "theory is our hedge against randomly accessing reality; it guides us to an intended reality and allows us to recognize it" (p.155).

Without certain theoretical knowledge, we would not understand the knowledge in order to make a successful transfer. Haskell argues that many transfers are made unsuccessful due to the lack of knowledge of theory that underlies the information where transfer is sought.

\section{Engage in hours of practice and drill.}

In the field of education, the idea of the old school drill and kill is discouraged. However, Haskell argues that practice and drill are necessary to build a solid knowledge base upon which transfer of learning can occur. He stresses that he does not approve of the drill and kill as seen in school houses where "methods of rote memorization and mindlessly drilling students in their lessons of readin' writin' and 'rithemetic" (p.171) were the norm; but he encourages reflective practice. Schon (1983) defines reflective practice as "the capacity to reflect on action so as to engage in a process of continuous learning" (p.102). When one is reflective in their practice, they are then able to build a solid knowledge base where adequate transfer can occur 10. Allow time for the learning to incubate.

Allowing time for the learning to incubate is a requirement for significant transfer to occur because it is time away from our own attempts to modify information to fit our own understanding, but to provide new insights or approaches at the subconscious level. Our culture 
of expectations teaches us to expect instantaneous success regarding whatever we do (Haskell, 2001). However, incubation time gives students the tools to patiently acquire new and genuine understanding.

11. Observe and read the works of people who are exemplars and masters of thinking.

According to Haskell (2001), it is crucial that learners read and observe exemplary works of transfer thinking. Reading the works of great exemplars of transfer thinking is important because it provides readers with first-hand knowledge of how critical a role reasoning has played in history's greatest discoveries, inventions, and innovations.

\section{Assumptions}

According to Haskell, transfer has a higher potential of occurring when the 11 principles are applied. The assumptions for this study were based on the current status of the application of these principles of the CDFFS preparation program. What follows is an examination of the principles within the context of the CDFFS pedagogical practices. The overarching assumption, that adherence to the 11 principles enhances the probability that transfer will occur in other instructional settings.

\section{Acquire a large primary knowledge base in the area in which transfer is required.}

Those who served as Servant Leader Interns (SLIs) in the Freedom Schools program are required to attend an extensive one-week training known as the Ella Baker Child Policy Training Institute in Knoxville, Tennessee. At this institute, participants engage in several sessions and activities that prepare them for a summer of service in the Freedom Schools program. The sessions focus on the extensive history of CDF and Freedom Schools (Jackson, 2011) along with providing them a solid foundation in the pedagogical practices unique to the Freedom Schools program (Jackson, 2009). Each year that participants return as SLIs or Site Coordinators, they 
are required to attend the training institute for rejuvenation and additional professional development. The acquisition of a large primary knowledge base of the Freedom Schools pedagogical practices supports the assumption that transfer could occur.

2. Acquire some level of knowledge base in subjects outside the primary area.

Freedom Schools is a unique program with norms that extend outside of the typical expectations of traditional school and other summer literacy programs. Therefore, there are very few outside subject areas that provide additional knowledge base of Freedom Schools' practices. As a result, principle two was not applicable to this study, therefore the potential for transfer of Freedom School precepts to teaching in the classroom beyond the FS setting was limited.

\section{Understand what transfer of learning is and how it works.}

Knowledge and understanding of transfer of learning into traditional school settings are not the goals of Freedom Schools or the national training institute. The program does not focus on giving SLIs the tools to transfer knowledge from Freedom Schools to the traditional classroom. There is no requirement for SLIs to be education majors seeking future careers as classroom teachers. Therefore, it was assumed that transfer would be somewhat minimized due to the lack of application of this principle in the FS pedagogical training.

\section{Understand the history in the area(s) that transfer is wanted.}

In the case of this study, transfer was wanted from Freedom Schools' settings to general classrooms across the United States. Freedom Schools' participants receive an extensive amount of information regarding the historical timeline of the American Civil Rights era including the creation of Freedom Schools. A historical timeline of education within America as a whole is not emphasized. However, it was assumed that those who enter the teaching profession have taken courses that discuss the historical context of American education. However, it cannot be 
assumed that the relationship between Freedom School history and general educational history will be juxtaposed.

\section{Acquire motivation, or more specifically, a "spirit of transfer".}

People who participate in Freedom Schools typically have a great passion and love for Freedom Schools. This passion comes from the love of the program, but more importantly from the positive effect seen among the students in the program. There is a chant performed daily during Harambee that states "Ooh, Ah, I love my Freedom Schools." The passion in which Freedom Schools participants have is like no other. Often, this passion carries on throughout their daily lives and begins to infiltrate into every aspect of their being while working in Freedom Schools. It was assumed that this spirit was carried into the teaching careers of those who become teachers.

6. Develop an orientation to think and encode learning in transfer terms.

The context in which learning takes place, determines whether one will be able to transfer that knowledge when necessary. One must learn to encode this knowledge so that it may be transferred when needed. Although the focus of Freedom Schools is not whether or not a SLI will transfer the knowledge gained in the program to a traditional classroom, this study questions whether or not the SLIs were transferring Freedom Schools practices to the different context of a traditional classroom. Because this was not an inherent part of Freedom Schools, the likelihood of transfer support was minimized.

\section{Create cultures of transfer or support systems.}

SLIs receive weeklong training during the national training institute and on the site training at their local sites throughout the summer. However, the goal of this training was not the transfer of the knowledge from Freedom Schools to the traditional classroom. There was no teacher 
development training or support for SLIs who choose teaching as a career path. Therefore, it was assumed that transfer was minimized as a result.

8. Understand the theory underlying the area(s) in which we want to see transfer.

Those who matriculate through teacher preparation programs through a traditional College of Education certification program are generally taught several educational theories prior to the completion of a program. However, those who chose an alternate route, often miss this information. Freedom Schools does incorporate "best practices" into its curriculum and classroom setup, but there is no evidence of explicit theoretical teachings within the Freedom Schools Integrated Reading Curriculum (IRC). The Freedom Schools program does not stress the importance of transfer of skills taught in Freedom Schools to areas outside of Freedom Schools. SLIs are not taught to carry their knowledge to future professions. It was assumed that participants who matriculated through a university teacher preparation program are well versed in education theory and would transfer those theories and ideologies into a classroom setting. In contrast, due to the lack of attention to this principle in the Freedom Schools preparation, it was assumed that teachers with FS training only would show less evidence of transfer.

\section{Engage in hours of practice and drill.}

SLIs receive a significant amount of practice on the information they are given during the Ella Baker Child Policy Training Institute. SLIs receive a highly intensive training on the IRC for three full days. During these days, they are allowed to practice and seek guidance on lesson delivery from the IRC. Upon delivery of the lesson, they are provided a detailed review. This support and critique continue during the summer through observations and trainings while at their Freedom Schools site. If a person is an SLI for more than one year, they receive training every year at a deeper level. This equates hours of practice and drill of the pedagogical strategies 
practiced in Freedom Schools. It was, therefore, more likely that these practices would transfer outside of Freedom Schools and into the traditional classrooms. Additionally, the structure of the daily debriefs offer a period of self-reflection each day. This ties directly to the idea of reflective practice. This extensive practice supports the notion that transfer may occur as a result. 10. Allow time for the learning to incubate.

Haskell suggests that learners have adequate time to think and ponder about new information in order for learning to take place. SLIs participate in many self-reflective assignments and activities. These activities are intended to assist SLIs in understanding their purpose for serving in Freedom Schools and to evaluate their practice as servant leaders. It was assumed that this practice of self-reflection would transfer for those who chose teaching as a career.

11. Observe and read the works of people who are exemplars and masters of transfer thinking.

As stated earlier, the Freedom Schools program does not make transfer of learning its focus. Therefore, it is not necessary for SLIs and SCs to read the works of people who are masters of transfer in order to successful transfer to occur. Because of this, it was assumed that transfer from Freedom Schools to regular classroom teaching would be limited because this principle was not directly applied.

\section{Definition of Terms}

Servant Leader Interns (SLIs)- College aged students who serve as the classroom teachers within the Freedom Schools program.

Site Coordinators (SCs)- Those who serve as direct onsite supervisors of the Freedom Schools program. 
Ella Baker Trainer (EBT)- The official consultants and trainers of the Ella Baker Child Policy Training Institute. They serve as the "face" of the training where they are given the task of training the SLIs and SCs to enter the classroom and properly conduct their Freedom Schools sites.

$>$ Ella Baker Child Policy Training Institute-The Ella Baker Child Policy Training Institute is a seven-day training held each year during the first week of June in Knoxville and Clinton, Tennessee. This institute serves as the official training for the CDF Freedom Schools programs. During this intensive seven-day training, approximately 1,500 Servant Leader Interns and Site Coordinators gather to receive training from over 100 presenters and speakers.

$>$ Children's Defense Fund (CDF)- Founded in 1973, CDF is a private, non-profit organization that serves as the parent organization of Freedom Schools. The mission of CDF is to "ensure every child a Healthy Start, a Head Start, a Fair Start, a Safe Start and a Moral Start in life and successful passage to adulthood with the help of caring families and communities" (Children's Defense Fund, 2014). Through their work with Freedom Schools and other initiatives, CDF strives to fulfill this mission in the lives of all children while paying particular attention to children of color and those with disabilities.

Integrated Reading Curriculum (IRC)-Often referred to as the "meat and potatoes" of the CDF Freedom Schools Program, the Integrated Reading Curriculum (IRC) is the literacy curriculum of Freedom Schools. The IRC consists of five components: Opening Activity, Main Activity, Cooperative Group Activities, Social Action/Conflict Resolution Activities, and Closing Activity 
Harambee- Harambee is Kiswahili for "Let's Pull Together" and is an integral part of the CDF Freedom Schools program. It begins the day of the scholars on a high note and gets them motivated for all that is to come. There are six components of Harambee: read aloud, motivational song, cheers and chants, recognitions, moment of silence, announcements.

Scholar- students within the Freedom Schools program are referred to as Scholars.

\section{Significance}

To date, there are no studies on the affect that Freedom Schools have on SLIs and/or SCs who chose to enter the teaching profession following participation in Freedom Schools training and implementation. This study served as a connection between Freedom Schools and its potential use in traditional classrooms. The findings from this study could potentially provide the base work for future research on the use of Freedom Schools' pedagogical practices in traditional classrooms.

\section{Limitations of study}

Three primary limitations arise for this study: participants, time, and bias. The small group of participants did not represent the number of SLIs who chose teaching as a career. This limited the generalizability of the study to other SLIs at other schools. Additionally, the participants had participated in the Ella Baker Child Policy Training Institute at different points in time. Although, the format of the training is similar each year, the presenters differ yielding the potential for differing experiences among the participants. The participants had participated at different Freedom Schools in different parts of the country. Although each site was under the direction of CDF, each site was run independently where differences do occur. Lastly, 
participants had varied years of teaching, which limited the understanding of what transferred from the Freedom Schools program and what had been learned simply through full-time experience.

I have worked for the CDFFS program, which in turn creates bias. The bias I have is positive transfer, which is the desired outcome. My assumption was that the teachers would transfer learned Freedom Schools instructional practices to the traditional classroom. This bias may have limited my ability to notice or focus on the lack of transfer, or the negative transfer of instructional practices.

Finally, a small amount of instructional practice was all that was examined, limiting the researcher to a complete picture of teachers' practices. I would have to be in a teacher's classroom more than 3-5 times to ensure a better understanding of the teachers' normal instructional practices. There was no guarantee that what I would see would only be what the participant wanted me to see.

\section{Summary}

This study is unique in that it describes the characteristics of former participants of a summer literacy enrichment program who currently work as full time teachers in a traditional classroom. For chapter 1, the purpose, research questions and significance for a study were described. I have chosen Transfer of Learning as the theoretical framework in order to fully describe the transfer, if any, of instructional practices from Freedom Schools to the traditional classroom. Based on a review of the principles as assumptions, within the context of the Freedom Schools setting, some low level transfer was possible, mostly due to the limited number of principles of transfer that were directly applied to the Freedom Schools program. 


\section{CHAPTER 2}

\section{RELATED LITERATURE}

\section{Transfer of Learning}

Fleishman (1987) defines transfer of learning as “...pervasive in everyday life, in the developing child and adult. Transfer takes place whenever our existing knowledge, abilities, and skills affect the learning or performance of new tasks...transfer of learning is seen as fundamental to all learning (p. xi). Since the early 1900s, psychologists have attempted to prove the existence of transfer. Behaviorist theorists of this time conducted experiments that confirming responses and skills established during a training phase were carried over, or transferred, to a task similar to the original learning situation of the training (Macaulay and Cree, 1999).

Thorndike (1901) describes the process of a subject's ability to apply what was learned from one situation to a second situation when the situations are similar. For example, Grabinger (1996) contended that people require "both content and context" (p.667) when transferring knowledge that they had difficulty in learning. Additionally, Analoui (1993) argues that transfer only takes place when the content is presented in a context similar to that which the content will need to be transferred. In short, all learning builds on previous experiences; a person can apply prior knowledge within a different domain from where knowledge was initially gained. Within the context of professional education and work settings, the process of transfer requires the appropriate selection of knowledge to assess and deal with a new situation.

\section{Hugging and Bridging}

In the late 1980s, a resurrection in transfer of learning emerged. Most of the focus of these studies concentrated on the failure of transfer of learning to lead to cognitive based 
strategies. The studies of Perkins and Salomon (Perkins\& Salomon, 1988; Salomon \& Perkins, 1989) are the most renowned of this time. Their studies have prevalence in education and training. Perkins and Salomon introduced two types of transfer referred to as low road transfer and high road transfer. Low road refers to the kind of transfer that happens automatically, requiring very little conscious thought. For example, one automatically begins to read when they open a book; interpreting a bar graph in the newspaper automatically triggers bar graph interpretation skills acquired in math; and a person's reflex skills automatically kick in when playing a video game (Perkins \& Salomon, 1988). The second type, high road transfer, "depends on deliberate mindful abstraction of skill or knowledge from one context for application in another" (p.25). For example, a chess player must deliberately contemplate a strategy for control of the center (Perkins \& Salomon, 1988). High road transfer often requires one to reflect on their previous knowledge to anticipate what content is needed for the particular context.

From their investigations, Perkins and Salomon conclude that high road transfer is problematic. Educators often expect it to occur automatically without any active intervention or preparation on their part. To provide a solution to this problem, the theorists construct a framework of instructional strategies termed, hugging and bridging. Hugging employs low road transfer and recommends that instruction directly engages the learners concerning the desired outcome. Perkins and Salomon (1992) give two examples of hugging:

1. A teacher might give students trial exams rather than just talk about exam technique, or 2. A job counselor might engage students in simulated interviews rather than just talking about good interview conduct. The learning experience thus "hugs" the target, performance, maximizing likelihood later of automatic low road transfer. (p.7) 
Theorists describe bridging as high road transfer and entail instruction that requires the educator to engage in processes that lead to connections, mindfulness, and metacognition. Perkins and Salomon (1992) also provide two examples of bridging:

1. A teacher might ask students to devise an exam strategy based on their past experience, 2. A job counselor might ask students to reflect on their strong points and weak points and make a plan to highlight the former and downplay the latter in an interview (p.8). The theorists argue that education can achieve transfer in abundance when it is designed for such an outcome.

Culture and Transfer.

Several researchers argue that race, ethnicity, and cultural differences influence transfer of learning (Caffarella, 2002; Roberson et al., 2009; Green, 2010, 2013; Closson, 2013). The argument stems from the type of previous knowledge needed to make a successful transfer. This is often referred to as "construction of knowledge" because learners create new meaning using what they already know (Halpern and Hakel, 2010). Therefore, what is learned and eventually transferred to another context depends greatly on what the learner knew before the start of the experience.

A person's epistemology of learning has a great effect on what knowledge they will transfer from one context to another. Haskell (2001) discusses personal epistemology and transfer of learning as highly influenced by the community in which the context occurs. Specifically, by the personal attributes, social group, and organizational systems that provide the context. Only then can the learning "be understood as a sociocultural process" (p.137). Herrington, Herrington, Hoban, and Reid (2009), stress the need for a culture of support for novice teachers for transfer of pedagogical practices from the university and student teaching to 
the classroom setting. According to the researchers, this support consists of mentors, time for reflection, and professional development.

Transfer of learning and teachers

Traditional approaches to teacher education are increasingly critiqued for their limited relationship to student teachers' needs and their meager impact on practice. Research in this field argues that university preparation programs are not providing future teachers with pedagogical strategies that will transfer from theory to action. More specifically, these researchers attempt to explain practices and conditions necessary for pre-service teachers to transfer the educational practices from university preparation programs to the teaching field (Putnam \& Borko, 2000; Darling- Hammond \& Bransford, 2005; Korthagen, Loughran, \& Russel, 2006; Zeichner, 2010).

Consensus amongst researchers is that university preparation programs must meet three criteria: shift in focus from the curriculum to the learner, link academic and practitioner knowledge, and restructure the student teaching experience. Korthegan et al. (2006) discuss the need for teacher preparation programs that shift the focus from a theoretically based curriculum to one that is embedded in the complete experience of a teacher. The authors expound on this idea by suggesting that

The learning of student teachers is only meaningful and powerful when it is embedded in the experience of learning to teach. As teacher educators, we need to be actively creating situations where this can occur and for it to be a natural part of teacher preparation. (p. 1030)

For this to occur, it is imperative that mentor teachers create situations in which pre-service teachers are required to incorporate education theories in practice. According to the authors, the theories that are present in university preparation curriculums are not regularly transferred by 
novice teachers because it is not put into practice during the student teaching process. A shift in focus from a theoretically based curriculum to practice in a classroom may increase the transfer.

It is argued that there is a disconnect between the university and the public school systems. This disconnect has led to a breakdown in transfer of theoretical pedagogies once one enters the classroom because theory has to switch to reality and there is a lack of mentorship by those university teachers who encourage the use of theory (Zeichner, 2010). To increase the probability of transfer and support teachers in the field, the author suggests that $\mathrm{Pk}-12$ teachers partner with university teachers to create campus courses that will better assist novice teachers in the field. This collaboration will unite theory and practicality of those theories thus leading to a greater chance of transfer of these practices.

Putnam and Borko (2000) argue that teacher preparation programs must be restructured to offer pre-service teachers a full immersion into the teaching practice throughout their studies rather than just for a semester or two of student teaching. The authors claim that the lack of transfer is due to the lack of hands-on preparation. They suggest an immersive study will greatly increase the transfer of instructional practices from university preparation programs into the classroom. These immersive programs will take the pre-service teacher and link them to a school for the entirety of their preparation time. They will involve themselves in several dialogue sessions with teachers throughout the school discussing, seeing in action, and practicing the theories in their syllabus. This will take the theoretical information and make it practical. Thus better equipping the student to become a teacher.

Transfer of learning is a theory that describes the transfer of content from one context to another. For transfer to occur, one must have a full understanding of the content and the ability to reflect on the context to transfer the appropriate content. This idea of transfer is one which is 
often perceived as a simple theory. However, real transfer is often a complicated and lengthy process.

\section{Freedom Schools}

Historical Development

Freedom summer of 1964. The effects of segregation proved catastrophic in the type of education offered to African-Americans in the Deep South, particularly, in the Mississippi Delta, where hardworking impoverished people lived. In 1964, the environment was hostile to people of color flooded with racism, and the effects of Jim Crow manifested in the disparities of schooling between black and white students. In 1963, the Student Non-Violent Coordinating Committee (SNCC) released a report on the state of Southern Schools. Perlstein (1990) summarizes the report as follows:

The report attacked both little school expenditures in Mississippi and unequal spending on black and white students. Claiming that racial inequality in public schools contradicted the intention of federal policies, SNCC advocated bringing the state up to national standards in per pupil expenditures, teacher salaries, average years of schooling, and literacy. (p.302)

This report served as the basis for proposing Freedom Schools throughout the Mississippi Delta.

Seeking to bring knowledge of fundamental rights, particularly voting rights, to this area, SNCC along with the Council of Federated Organizations (COFO) developed the 1964 Freedom Summer. Through COFO, SNCC activists brought hundreds of college students, mostly White, to the Mississippi Delta to dedicate their summers to conducting extensive voter registration drives and teaching in 41 Freedom Schools within the African American communities (Perlstein, 1990). Many of the students who were recruited to spend the summer in the Deep South were 
unaware of the reality of the tension that brewed throughout this area. Like many in the United States, they had seen pictures and heard stories but never experienced this form of racism in reality.

During the summer of 1964, over 2,000 middle and high school students participated in the Mississippi Freedom Schools (Hale, 2011). Charles Cobb, a prominent member of SNCC, was the principal organizer of the Freedom Schools. Cobbs' primary mission was to provide alternative schools that

Could supplement what Black students were learning in their high schools, give them a broader intellectual and academic experience that they could take back to their regular classes and share with their fellow students, and form the basis for statewide student action such as a school boycott. (Ligon and Chilcoat, 1999, p. 45)

The 1964 Freedom Schools produced many positives for the people of Mississippi. The adults increased knowledge of voter registration and registered to vote; students became young activists; the Freedom Schools newspapers gave teenaged children a voice; and the children who participated gained pride and knowledge of their history (Sturky, 2010). The 1964 Freedom Schools lasted for only one summer. However, the Children's Defense Fund rejuvenated the Freedom Schools program in the early 1990s.

Present-day freedom schools. Unfortunately, 50 years later, many of the disparities in education between African Americans and their White and Asian counterparts stated in the 1963 report still exist today (National Center for Education Statistics, 2015). Since 2009, African Americans and Hispanics have had the lowest performance scores. The academic performance of the nation's 12 th graders in math and reading has not changed since this time. Additionally, the Black-White gap in math and reading scores in 2013 was 30 points. The Black-White 
achievement gap is not solely evident in reading and math scores, but in a multitude of difficulties that contribute to and result from unequal opportunities. A few of these problems are: overrepresentation of black males in special education, isolation or removal of black males who are seen as discipline problems, the tracking of black students in low-level classes, the disproportionate number of black high school dropouts, and the number of black students educated in schools with the least amount of resources and least experienced teachers (Horsford, 2011). The Freedom Schools program is working to close those educational gaps.

Following the summer of 1964, the Freedom Schools program did not return to the Mississippi Delta in the same format. In 1992, Marian Wright Edelman and the Black Community Crusade for Children (BCCC) brought back the Freedom Schools Program in response to the education crisis in the black community. Watson (2014), states, "The same mission from the 1964 Freedom Summer, is witnessed throughout today's CDF Freedom School Program”. (p.178)

Since 1992, the CDFFS program has expanded from two cities to influencing children nationwide. In the summer of 2015, Freedom Schools served over 12,700 children in 107 cities and 28 states (and Washington, D.C.). Since 1995, over 125,000 children and families and have been touched by the CDF Freedom Schools program experience and more than 15,000 college students have been trained to deliver this empowering model (Children's Defense Fund, 2016).

There is very little research on the current state of Freedom Schools. Most of the literature that does exist come from those within the Freedom Schools "family", meaning those who have some ties to the program. However, all research present accredit Freedom Schools in changing the views that young people, particularly those of color, have regarding reading (Jackson, 2009; Smtih, 2010; Dunkerly, 2011; Groenke, Bennett, Hill, 2012; Watson, 2014). 
This changing of views is a result of scholars' participation in the Integrated Reading Curriculum (IRC).

Often referred to as the "meat and potatoes" of the CDFFS program, the IRC is the backbone of Freedom Schools. The IRC consists of five components: Opening Activity, Main Activity, Cooperative Group Activities, Social Action/Conflict Resolution Activities, and Closing Activity. Giroux (1986) argues for a pedagogy that "is attentive to the histories, dreams, and experiences that....students bring to school" (p.64). By presenting scholars with books that relate to their personal daily lives, this critical style of learning is achieved. The primary activity of the IRC includes an in-depth discussion between the Servant Leader Intern (SLI) and the scholars. During this discussion, the SLI has scholars take a critical look at the characters analyzing their actions and relating them to their daily lives. Additionally, scholars reflect on the rights and power in which the characters possess (Smith, 2010). The IRC study lends the SLI as a facilitator who is fully involved in the learning process.

Repositioning the SLI from the all-knowing role of the teacher to a facilitator who learns alongside the scholar. Freire (1968) presents the all-powerful teacher. He discusses the idea of a teacher having all knowledge that they must "deposit" into the students. Instead, he argues for a teacher who does not view himself as the holder of knowledge, but one who can learn from the students and make learning a two-way street. This is the primary view of education within the Freedom Schools Program. The SLI is not regarded as the possessor of knowledge, but one who facilitates discussion so that learning can occur. This is seen in the reading circle within the classroom. The SLIs are trained to stay seated when holding discussion or reading the weekly book. This is, so the scholars do not see them as an all-knowing being who stands over them, but someone who is learning as much from the scholars as the scholars are learning from them. 
For the past four years Freedom Schools Partners (a community organization that provides CDF Freedom Schools Programs to children in the Charlotte, North Carolina metropolitan area) has partnered with the University of North Carolina at Charlotte to gauge impact of the IRC through measuring the gains in reading of the 700 plus scholars who attend Freedom Schools in the North Carolina area. The results of the study are as follows:

- Four consecutive years of data show that approximately $90 \%$ of Freedom Schools scholars in Charlotte maintain or gain in their reading ability while participating in the summer program.

- Using the Basic Reading Inventory (Johns, 2008), scholars in grades 3-8 gained, on average, over a year in reading ability. Scholars in grades K-2 gained, on average, about half a year in reading ability.

- On average from 2010 through $2013,56 \%$ of scholars improved their reading ability, and 33\% maintained their reading ability

- This is compared to most low-income children who lose 2-3 months of reading ability in the summer months. (Taylor, Lara-Cinisomo, and Glover, 2013)

The make-up and mission of current day CDFFS program are very similar to that of the 1964 Freedom Schools program. Jackson and Howard (2014) describe the Children's Defense Fund Freedom Schools (CDFFS) program as a "counter-narrative for students, parents, communities, and the servant-leader interns in contrast to the continued inadequacies of public education for children of color, particularly African American children and poor children" (p.158). The Freedom Schools movement creates a model for instructing students that is inclusive while being culturally relevant and responsive to the needs of African American students to belong, engage, and learn. The remainder of this review will look at two major 
categories in which the current research of Freedom Schools is established, inclusiveness and cultural relevancy and responsiveness.

Inclusiveness. Wlodkowski and Ginsberg (1995) establish inclusion as a condition necessary for CRP to take place. According to the authors, inclusion is the creation of a learning atmosphere where everyone involved, the students and teachers, feel respected by and connected to one another. The CDFFS program provides this atmosphere for scholars. Smith (2010) conducted a study of a particular Freedom Schools program exploring how regimes of truth are created and fostered in a CDFFS program. Smith uses critical pedagogy as the framework for this study. According to Smith (2010),

Critical pedagogy honors the notion of contextualized thinking and considers the effect knowledge has on cognition and behavior. It is a pedagogy that fosters an interchange among reflection, conceptualization, and action. Furthermore, it engages a constant cycle of knowledge construction and ripens our understanding of particular knowledge bases. (p.191)

Given that critical pedagogy focuses on the ways in which knowledge affects cognition and behavior, Smith zooms in on Foucault's interpretation of critical pedagogy which focuses on regimes of truth or the "general politics of truth: that is the types of discourses which it [a society] accepts and makes function as true" (as cited in Smith, 2010, p. 192). The particular discourse studied is what those in the CDFFS program call "The Freedom Schools Way." "The Freedom Schools Way" is a form of discourse that "endorses empowerment, reflection, and stewardship" (pp. 193-194) giving scholars inclusiveness.

Through the use of observations, survey, and interviews Smith found that "The Freedom Schools Way" promoted inclusiveness through its particular discourse in general talking at the 
site and the IRC. Smith argues that the use of titles such as scholars describe the children in Freedom Schools and servant leaders to describe those who serve as teachers within the classroom "perpetuates an identity for young people, giving them the authority to possess and construct ideas". (p. 198)

Smith describes the IRC as being

Structured in ways that seek to help scholars critically think about how their actions influence themselves and society. Each novel has a daily lesson plan that draws on the experiences of characters introduced. The aim is to give scholars exemplars to contemplate significant life events and to provide space for them to make connections between the characters' experiences and occurrences relevant to their lives. (pp. 201-202)

The interviews found connections that scholars and servant leaders had with the texts read on a weekly basis. The study determined that over one-half of the scholars expressed having a relationship with the characters in the books. Not only were relationships made with the characters, but the scholars describe applying the knowledge gained in their reading to their personal lives with topics such as "ending racism, helping to improve their communities, changing how the USA is run, and creating a healthy environment” (p. 203).

Green (2014) continues with this notion of inclusiveness through the connection of the scholars to curricular activities. Green refers to this as linguistic capital or "the intellectual and social skills attained through communication experiences in more than one language and/ or style" (p. 171). Green describes the use of poetry, rap, and plays during IRC activities as a form of expression. Additionally, the use of chants focused on academic engagement seen throughout the site as examples of linguistic capital due to the amount of Black English used in these 
expressions. She suggests the language and style used in Freedom Schools activities is one that scholars can relate and connect and often used in their homes and one in which they are usually more comfortable and fluent. Although many of the novels and chants used Black English, American Standard English is emphasized thus teaching students the process of "being culturally flexible and successfully navigating through mainstream culture while maintaining one's identity" (p. 171). Green concludes the CDFFS program promotes inclusiveness through the use of cultural capital given to the scholars.

The inclusiveness provided by the CDFFS program is essential in the mission of the program to close the achievement gaps between children of color and their white and Asian counterparts.

Cultural Relevancy and Responsiveness

Coined by Gloria Ladson-Billings (1995a), Culturally Relevant Pedagogy (CRP) is defined as:

Specifically committed to collective, not merely individual, empowerment. Culturally relevant pedagogy rests on three criteria or propositions: (a) students must experience academic success; (b) students must develop and/or maintain cultural competence; and (c) students must develop a critical consciousness through which they challenge the status quo of the social order. (p.160)

CRP seeks to make the connections between student and teacher, student and learning, and student and success. Through the use of a student's culture, they are empowered to tackle real issues, have hard conversations, and discover and share who they are as a person, not just a student. CRP is framed within three major components: Academic Achievement, Cultural Competence, and Sociopolitical Consciousness (Ladson-Billings, 1992, 1995(a), 1995(b); 
Milner, 2010; Payne, Laughter, Gilbert, Hoffman, \& Simpson, 2013). CRP not only addresses the ways in which teachers ought to teach students, but it gives students a voice and tools to advocate for themselves. Teachers also acknowledge the culture of students and develop relationships that enable them to better teach students and meet their needs.

The research describes CRP in action in traditional school settings (mostly public schools) through three categories: teacher support, curriculum creation, and district/school culture.

Teacher support. Teachers who embrace culturally relevant pedagogical practices understand the importance of modeling, scaffolding, and clarifying challenging curriculum (Brown, 2003; Conrad, Gong, Sipp, \& Wright, 2002; Gutierrez, 2000; Hollie, 2001; Jimenez, 1997; Jimenez \& Gertsen, 1999; Lee, 1995; Sheets, 1995; Stuart \& Volk, 2002). These teachers understand the difficulties of the curriculum and mold it to fit the needs of their students. Several of the teachers described in studies explicitly modeled the material using the practice of "thinking aloud" which illustrates the steps required to complete a project as the teacher "thinks aloud" or verbalizes the steps taken. Additionally, the teachers described by the researchers encouraged collaboration between students, outlined expectations, and monitored student learning and progress.

The second way in which teachers provided support in classrooms where the pedagogical practices of CRP were evident was through using student strengths as a starting point for instruction. This was done by presenting students information on the lowest level possible to build their background knowledge and strengths before moving on to more challenging material (Brenner, 1998; Brown, 2003; Powell, 1997; Sheets, 1995). This method gave students a basic starting point while giving them small victories throughout the learning process. 
Curriculum Creation. Ladson- Billings (1995) suggests that CRP must develop in students a sense of cultural competence, a "dynamic or synergistic relationship between home/community culture and school culture" (Ladson-Billings, 1995, p. 467). Culturally relevant teachers understand the importance of adjusting the curriculum to fit the cultural background of students. In classrooms, where this pedagogical practice takes place, the curriculum incorporates several aspects of the students. These adjustments are made in a variety of ways: using the works of authors of color (Bell \& Clark, 1998; Hefflin, 2002; Hickling-Hudson \& Ahlquist, 2003; Hollie,2001; Jimenez, 1997; Newell \& Sweet, 1999; Powell, 1997); use of familiar manipulatives, such as dominoes, in math lessons (Cahnmann \& Remillard,2002; Guha, 2006); unique forms of activities for physical education, familiar and unfamiliar to students (Flory \& McCaughtry,2011); and the use of other items specific to a particular group, such as healing herbs (Hickling-Hudson \& Ahlquist, 2003). In addition to enhancing the curriculum, teachers rely on the knowledge that students bring with them to the classroom. This knowledge is both academic and cultural or commonly referred to as "street knowledge". This is denoted as students' funds of knowledge. Culturally relevant teachers incorporate funds of knowledge into their curriculum through using examples of students' experiences and lives when teaching concepts (Hefflin, 2002; Howard, 2001a; Jimenez, 1997; McGill-Franzen, Lanford, \& Adams, 2002; Tate, 1995), resulting in an instant connection between the student and the curriculum.

District and school culture. Districts and schools that embrace CRP encourage relationships between schools and communities. The schools and districts in some of the studies also made cognizant efforts to involve families and communities in the day-to-day decisions of the school. This included making families and communities apart of the governing body of the school (McGill-Franzen et al., 2002). This "open doors" approach and sharing of the power 
within the school resulted in schools where families and community members felt welcomed and able to assist with the success of the school and district.

Student's response to culturally relevant pedagogy. Much of the research on CRP studies teaching practice and teachers' abilities to implement the theory as pedagogy in the classroom. However, Howard (2001) examines the student's response to instruction that is culturally relevant. Through the observations and interviews of 17 elementary aged students, Howard's research identified three major themes of the effect that culturally relevant instruction has on students: "(1) the importance of caring teachers, (2) the establishment of a community/familytype classroom environment, and (3) education as entertainment" (p. 136). The participants of the study described a caring teacher as one who provides affection, encouragement, understanding, and sternness. The students declared that they tended to work harder and behave better for a teacher who cared about them as a person and not just as a number in their classroom.

The second theme in this study described the classroom as a community/family. This connection within the classrooms comes from the establishment and practice of rituals and traditions unique to the particular teacher and his/her students. This created a parent-child like a relationship within the classroom. As a result of this type of classroom relationship, "the students stated that they were just as willing to share confidential information, seek advice, and attempt to gain approval from their teachers in ways they would from their own parents" (p. 143).

Lastly, students in Howard's study discussed the abilities of culturally relevant teachers to make learning a fun and exciting process. These students explained their willingness to focus on the information taught when it was entertaining to them. They also described the difference in their achievement in classes deemed "boring" and those they described as exciting. The 
participants of this study frequently mentioned how much they learned and the ways in which these teachers made them smarter. Additionally, they stressed the perception that these particular teachers believed in them and their ability to achieve. This is something that many of the students expressed as not having in previous classes.

Culturally relevant pedagogy and freedom schools. The IRC embodies the practices of CRP. This literature provides positive messages to scholars and encourages them to read more often (Groenke, Bennett, \& Hill, 2012; Jackson \& Boutte, 2009) thus exemplifying the CDFFS programs goal of "making scholars fall in love with reading." Jackson (2009) describes the literature presented in the IRC as liberatory literature, a term coined by Virginia Hamilton and defined as "literature that allows the reader to travel with characters in the imagined world of the book and bear witness to the character's trials, sufferings, and triumphs" (p.109).

In addition to its academic focus, CDFFS strives to instill social consciousness in scholars in hopes that they will transfer this consciousness into social action. The Freedom Schools curriculum has a social action component embedded in the curriculum as well as other activities throughout the program centered on social action. The social action activities consist of activities such as community clean up, voter registration, and community beautification. Bethea (2012) studied scholars who attend a Freedom Schools program in the Bay area. She concludes that the scholars who participate in Freedom Schools show improvement in alternate-solution thinking and can give more efficient solutions to problems through the use of conflict resolution strategies learned. Furthermore, participation in Freedom Schools help "promote social action values and a desire to participate in social action activities. Through social action activities (e.g., community service, cleaning up community parks) and advocacy projects, scholars learn how to access resources and to create them where they are lacking" (p. 450). This study suggest 
educators must not be afraid to teach students to question political ways, stress the fact that education is the only freedom we have, create thinkers that are essential and will challenge traditional thought, bridge the gap between learning and everyday life, make students aware, focus on culture and cultural politics, and create an environment where learning is linked to social change. The social action activities foster this type of education and social awareness within the scholars.

The essence of Freedom Schools is to empower scholars in taking a critical look at the world in which they live while "providing a culturally relevant schooling experience for students, parents, communities, and teachers (Jackson \& Howard, 2014, p.159). The CDFFS comes from an extensive history of knowledge. Stemming from a deep culture of literacy and innovation, Freedom Schools instill in its Scholars the requirement and necessity of a sufficient education. Moreover, the CDFFS program offers students a culturally relevant educational experience incomparable to a "traditional" school setting, with the focus on making Scholars fall in love with reading. 


\title{
CHAPTER 3
}

\section{METHODOLOGY}

\author{
Purpose
}

The purpose of the study was to investigate the transfer of instructional practices from the CDFFS program to the traditional classroom by teachers who served as servant leader interns (SLIs) in the Freedom Schools program.

\section{Research Questions}

1. What levels of Freedom Schools' instructional practices are transferred into traditional classrooms, as observed among former Freedom Schools Servant Leader Interns (SLIs) who are current classroom teachers?

2. What practices gleaned from SLI experiences, do K-12 teachers, who served as SLIs, name as influential experiences in their teaching practice?

3. What evidence is there that specific types and levels of transfer occur through the Freedom Schools practices in use in the current classrooms of SLIs?

\section{Research Design}

This research consisted of a multiple case study of three in-service teachers who served for 1-10 years as SLIs or site coordinators within the Freedom Schools program. Yin (2003) states that a researcher should use a case study design when: (a) you cannot manipulate the behavior of those involved in the study; (b) you want to cover contextual conditions because you believe they are relevant to the phenomenon under study; or (c) the boundaries are not clear between the phenomenon and context. The study at hand follows all three of the criteria stated above. The researcher sought to understand the transfer of instructional practices from Freedom Schools to the traditional classroom; the researcher was unable to change the teaching practices 
of the participants; the context in which the instructional practices took place was crucial to the study, and the boundaries between the context and the instructional practices were unclear. Baxter and Jack (2008) discuss the collaborations between the researcher and the participants along with the participant's ability to tell their reality as an advantage of using multiple case study. In this study, the participants told their stories through interviews. The researcher used these stories, along with observations and a survey, to determine the transfer of Freedom School instructional practices into the classrooms of the three participants.

\section{Settings}

The study took place in three different schools all located in Louisiana. Two of the schools were located in urban areas while the third located in a rural area. Below is a description of each school.

Oakdale Park Elementary School was a public Pre-Kindergarten (Pre-K)-5th grade school located in a large urban area of Louisiana. The school had an enrollment of 565 students with 99\% of students African American and 93\% on free and reduced lunch. The school's motto "Teamwork makes the dream work" was posted throughout the school and emphasized daily by the principal. As a result, there was an underlying expectation for each teacher to go above and beyond their job description to enhance the school. Such activities included after-school tutoring, summer programs, joining the PTA, making frequent house calls to build relationships with families, and home visits. The principal also made known his goal for the school to become a National Blue Ribbon school through verbal communication and posters throughout the school depicting this objective. The classroom observed was located in a trailer in the back of the school. This colorful classroom covered in student work, numbers, the alphabet, and pictures immediately identified itself as a Pre-K class. 
Mitchell Jefferson Charter School was a Pre-K-6th grade school located in the mid-city neighborhood in a large urban city in Louisiana. This school was one of many charter schools to influx the state of Louisiana following Hurricane Katrina. The school had an enrollment of 522 students with $42 \%$ African-American, 36.4\% White, and 6.5\% Hispanic. $60.3 \%$ of the students enrolled were eligible for free and reduced lunch. Mitchell Jefferson was named after a pioneer in education for this particular city. The school was open in 2010 claimed to be the most racially and economically diverse school in the city. Although located in a median income area of the city, the school's students come from all demographic backgrounds. The students hailed from single-parent homes, two parent homes, and parents from blue-collar and white-collar professions. The school placed a heavy emphasis on language, the arts, and developing the whole child. The school was also a member of the International Baccalaureate (IB) Organization offering IB classes to their students.

Clarksville High School was a public 7th-12th grade school located in a rural area of central Louisiana. The school had an elaborate history and dates back to 1856. The school was full of tradition; many students are fourth and even fifth generation students to this particular school. It was told that the entire town in empty during football season because every resident was at the local stadium cheering for the high school football team.

Clarksville High School was a very diverse school for this part of the state. The school has 962 students enrolled with 44\% African American and 52\% White with 68\% of the students eligible for free and reduced lunch. The current a graduation rate was $67 \%$, with $41 \%$ of students on or above grade level. The school had a long history of violence and racial tension. However, the current administration, both school and district level, were working fervently to change the reputation of the school. 


\section{Participants}

Recruitment of participants involved a search of teachers who participated as SLIs in Freedom Schools within the local geographic region of the researcher, and currently served as classroom teachers. This information was obtained by contacting local Freedom Schools site coordinators and sponsors. Once this list was received, the researcher made contact with potential participants to seek involvement in the study. Lastly, emails were sent to request permission from school leaders to conduct research in schools where potential participants taught. Once all letters of permission were acquired, and IRB permission was granted, the study began.

The participants for this study consists of three current classroom teachers, grades Pre-K12. These participants had served at least one summer as SLIs within the Freedom Schools programs before employment as a classroom teacher. Each of the teachers held teaching certificates for the state of Louisiana. This was noted due to a large number of teachers who currently work in the state while pursuing teaching certification.

\section{Participant 1}

Faith was an African American female from Louisiana and a 2nd-year Pre-K teacher at Oakdale Park Elementary School. Before teaching Pre-K, she served as a 3rd-5th grade math interventionist for a semester. Faith began working with Freedom Schools seven years ago. She has served three years as a Servant Leader Intern (SLI), two years as a Site Coordinator (SC), and is currently serving her 3rd year as an Ella Baker Trainer (EBT).

Initially, Faith entered college with another major, besides education, in mind. She described the influence that Freedom Schools had in her changing her major to education. 
Faith: I've always loved children, and I've always known I wanted to work with children in some way. I tried, well thought for like a year that I'd be a pediatrician, but then that math and science thing kicked in, and I was like you know what that's not for me. But then I met Freedom Schools, and it changed my life! I just liked interacting with children; I like getting down on their level, having conversations. It's something about that moment when they have that epiphany; it's like I helped you get there. When I realized that I could have these experiences every day with children, I decided to become a teacher.

\section{Participant 2}

Jacob was an African American male from Mississippi, who taught fifth and sixth grade Social Studies and Science at Mitchell Jefferson Charter School. Jacob began working with Freedom Schools in 2005 while in college. He started as a volunteer, and was eventually hired as an SLI. Jacob worked with the Freedom Schools program for seven years in the capacity of SLI for four years and as a site coordinator for three years. Jacob had been a classroom teacher for five years, previously teaching 2nd grade.

Jacob described the relationship with his band director as one of his most influential and impacting relationships with a teacher. He describes this impact below:

Jacob: I had a band director who grabbed me because I was hanging out with the wrong people in high school. He was like no you're going to be in my band, and play this instrument. That's what saved me from going the other way. In high school, my other friends didn't have the music. They didn't have practices after school; they had opportunities to sell drugs or hang out and go to the club. I had band to go to after school. Then I had to go home and do homework and practice on band music. My teacher had the foresight to say, "Ok, this kid has something different" and him pulling me in and 
saying "You're going to be in my band program" changed my life. The conversations we had and him putting his all into me and telling me that I could be someone had a significant impact. I believe if I didn't have that band program in high school, I would have fell by the wayside.

Jacob entered his college career on a different path than education; however, he credited his participation in Freedom Schools as the catalyst for his transition into education as a career choice.

Jacob: The relationships that I built with those parents and scholars in Freedom Schools changed my mind. To see a kid cry simply because they miss their city and the friends they had (in New Orleans prior to Hurricane Katrina); they were uprooted, and it just touched my heart. And I was like I just want to be around students to make their life better by making my life better, just by helping them out.

\section{Participant 3}

Janet was an African American female from South Carolina, who taught 8th grade English at Clarksville High School. She was in her 6th year of teaching and relocated to Louisiana as part of a teacher corp. She had participated in Freedom Schools since she was in elementary school serving as a scholar for nine years, a junior SLI for three years, an SLI for five years, an SC for three years, and as an Ella Baker Trainer for three years. Before teaching 8th grade, Janet taught high school Journalism and Publishing.

Throughout our interviews, Janet regularly spoke about her 9th grade English teacher who greatly impacted her life as a student and as a teacher. She described this teacher below: Janet: I met (teacher), my ninth grade year. She was my English teacher. I was a little rough around the edges by the time I got to high school, but this lady she stayed on me all 
the time. She was like that teacher that would ask, "Why are you so angry? Write it down, don't tell me." She was that teacher. The one who'd say, "I will be your best friend and I will fail you if you don't do my work." It's funny because I tell my kids that now, "I will smile in your face, and I will send you to summer school." I remember after ninth grade, I wanted to be like (teacher), I wanted to do everything like (teacher). I pretty much have modeled my life after this woman's life. I went to the same college that she did, pledged the same sorority as her. My first year of teaching, I taught at the same school that I graduated from because I wanted her to be my mentor my first year of teaching. From ninth grade on up, she's been in my life. She would always say, "If what you're doing right now you have to ask yourself, will (teacher) be proud of you, then you shouldn't be doing it." I pretty much owe my whole life to her.

There were several similarities between the participants. Each participant discussed the influence of teachers in their lives. They identified, at least, one teacher whom they considered influential to their educational life and their current profession as a teacher. Two of the participants credit Freedom Schools as the reason behind them choosing to teach as a profession. They each entered college with a major outside of education but changed the major to education after working with the scholars in Freedom Schools. In addition to having similar experiences in Freedom Schools and with influential teachers, each participant discussed negative and positive experiences in their educational career that drives their current teaching practices. Additional characteristics of the participants are depicted in the table below. 
Table 3.1

Demographic Characteristics of Participants

\begin{tabular}{|l|l|l|l|l|l|l|l|}
\hline Participant & \multicolumn{2}{|c|}{$\begin{array}{l}\text { Gender } \\
\text { Ethnicity } \\
\text { Faith }\end{array}$} & $\begin{array}{l}\text { F } \\
\text { Eears in } \\
\text { CDFFS }\end{array}$ & $\begin{array}{l}\text { Positions } \\
\text { held in } \\
\text { CDFFS } \\
\text { American }\end{array}$ & $\begin{array}{l}\text { \#of years } \\
\text { Teaching }\end{array}$ & $\begin{array}{l}\text { Subjects } \\
\text { \&grades } \\
\text { currently } \\
\text { teaching }\end{array}$ & $\begin{array}{l}\text { Subjects } \\
\text { \&grades } \\
\text { previously } \\
\text { taught }\end{array}$ \\
\hline Jacob & M & $\begin{array}{l}\text { African } \\
\text { American }\end{array}$ & 7 & $\begin{array}{l}\text { SLI, SC, } \\
\text { EBT }\end{array}$ & 2.5 & $\begin{array}{l}\text { Pre- } \\
\text { Kindergarten }\end{array}$ & $\begin{array}{l}3^{\text {rd }}-5^{\text {th }} \text { Math } \\
\text { Interventionis } \\
\text { t }\end{array}$ \\
\hline Janet & F & $\begin{array}{l}\text { African } \\
\text { American }\end{array}$ & 23 & $\begin{array}{l}\text { Scholar, } \\
\text { SLI, SC, } \\
\text { EBT }\end{array}$ & 5 & $\begin{array}{l}5^{\text {th }} \text { and } 6^{\text {th }} \\
\text { Science and } \\
\text { Social } \\
\text { Studies }\end{array}$ & $2^{\text {nd }}$ Grade \\
\hline
\end{tabular}

Table 3.1.

The following are the names for the acronyms used in Table 3.1: Children's Defense Fund Freedom Schools (CDFFS), Servant Leader Intern (SLI), Site Coordinator (SC), and Ella Baker Trainer (EBT)

\section{Data Sources and Collection}

Survey

Bryman (2008) defines a self-administered survey as a survey where "respondents answer questions by completing the questionnaire themselves" (p.216). Before the first observation, participants received a questionnaire via Google Docs, a web-based word processing program. The survey asked basic demographic information, information regarding the number of years teaching and subjects taught, and involvement in the CDFFS program. The questionnaire is found in Appendix B. The researcher retrieved the data through the online program. Google Docs took the information the participant entered and organized it into a spreadsheet. The researcher then obtained the spreadsheet from the online program for analysis purposes. 


\section{Observations}

The Freedom Schools Pedagogies Teacher Observation Record (FSPTOR) protocol (Jackson, n.p.) was developed as part of a study that focused on teachers who attended the CDFFS Teacher Institute. This institute trained current classroom teachers in Freedom Schools pedagogies for use in their classrooms. The protocol used six components of the CDFFS

program: (1) classroom environment, (2) approaches to instruction, (3) culturally relevant curriculum, and materials, (4) learning theories, (5) authentic assessment, and (6) establishing high expectations and engaging students. SLI's are extensively trained on these six components. To date, the instrument was developed, used locally, but no reliability or validity figures had been calculated. The document is located in Appendix C.

Three classroom observations, lasting 3-4 hours per visit of the participants, were conducted using the FSPTOR. During the observations, the researcher served as a nonparticipant observer and used the protocol to assess the frequency of CDFFS pedagogical practices used in the classroom.

Interviews

Seidman's Three Interview Series was used to collect interview data. Seidman (2013) describes this interview model as a means to "exploring the meaning of people's experiences in the context of their lives" (p.20). The series consists of three separate interviews each lasting approximately 45-60 minutes. This interview model is one approach to Seidman's four-part phenomenological interviewing method. Each part of Seidman's phenomenological method focuses on a separate interpretation, or theme, of the human experience. The themes are: the participants' overall experience, the true essence of the experience, the lived experience, and making meaning of the experience. Seidman argues the understanding of each of these themes 
give the interviewer structure and technique that offers guidance and grounding for the interview process.

For the first interview, participants were asked to describe their educational experiences from as far back as they can remember to present day. They were also asked to describe participation in the Ella Baker Child Policy Training Institute. In the second interview, participants described experiences of their day at work, from the time that they enter the building until they leave. They were asked to describe their interactions with students, parents, coworkers, administrators, etc. They were also asked to give a summary of their teaching practices. In the third and final interview, participants reflected on the meaning of their teaching experience. In this interview, participants reflect on the intellectual and emotional connection between work and life, and what made them the teacher that they are today. All interviews were recorded using Evernote technology and transcribed. The full interview protocol is found in Appendix A.

\section{Data Collection Timeline}

Data were collected in the spring of 2015 from April to June. Three observations and interviews took place once a week over the course of three weeks per participant. Following the interviews, the researcher transcribed the interview and presented the transcription to the participants for member checking.

\section{Data Analysis}

As mentioned in Chapter 1, the theoretical framework underlying this research was based on Haskell's (2001) theory or transfer. He defines transfer as "applying what we have learned in the past to understanding and grasping the present" (p.75). In short, all learning builds on previous experiences. Using this definition of transfer, data analysis took place in three stages. 


\section{Stage 1}

The first phase of analysis consisted of a complete comparison of the participants' demographic information. The demographic information for each candidate was obtained through an electronic survey. The data were compared based on the information provided, and participants were organized into a hierarchy based on the information. The participant with the most amount of Freedom Schools experience was placed at the top while the participant with the least amount of experience was placed at the bottom.

Stage 2

The transcribed interview data were analyzed using NVivo 10 software for coding purposes. NVivo 10 is a software package that allows users to classify, sort and arrange data (QSR International, 2015). The six levels and 14 types of transfer served as nodes to classify the statements in the transcribed interviews. The transcribe data were inserted into the program and placed into the node in which it most precisely identified with. Following this analysis, the nodes were further inspected to create an overall level and type of transfer for the data. This data was then divided into the domains representing the levels and types of transfer that occurred. Coding themes for these data are found in Appendix D.

Stage 3

Finally, observation data were analyzed using the domains presented through the analysis of data in the NVivo 10 software. The notes and memos for the observations were used in this analysis along with the results of the observation protocol. The data were triangulated with the interviews and survey results to establish the trends in transfer across the group. 


\section{Summary}

For Chapter 3, the researcher described a multiple case study of three teachers as the research design methodology. Through classroom observations, interview of participants using Seidman's Interview Series, and demographic information expressed in the questionnaire, the researcher was able to present a glimpse into the transferability of instructional practices used in the Freedom Schools to the regular classroom setting. 


\section{CHAPTER 4}

\section{FINDINGS}

\section{Purpose}

The purpose of the study was to investigate the transfer of instructional practices from the Children's Defense Fund Freedom Schools (CDFFS) program to the regular classroom by teachers who served as servant leader interns (SLIs) in the Freedom Schools program.

\section{Research Questions}

1. What levels of Freedom Schools instructional practices are transferred into traditional classrooms, as observed among former Freedom Schools Servant Leader Interns (SLIs) who are current classroom teachers?

2. What practices gleaned from SLI experiences do K-12 teachers, who served as SLIs, name as influential experiences in their teaching practice?

3. What evidence is there that specific types of transfer occur through the Freedom Schools practices in use in the current classrooms of SLIs?

\section{Presentation of Findings}

The findings were addressed in relationship to each research question and documented by the participant. The examination of each level and type of transfer was done through the comparison of domains derived from the transcribed data and the FSPTOR. The domains and transfer were first described within the context of Freedom Schools, followed by the context in participant's classroom. Finally, validation of the domain as level or type of transfer was discussed. At the end of the chapter, a cross analysis showed the levels and types of transfer between the teachers. 
Participant 1 Jacob

Level of transfer. Of the levels of transfer, Jacob most precisely aligned with near transfer. According to Haskell (2001), near transfer is the transfer of previous knowledge to new situations that are similar, but not identical, to a previous situation. Regularly, near transfer is seen in the transfer of procedures from one situation to another. It was determined that Jacob's level of transfer, near transfer, occurred in one primary domain: classroom management.

Classroom management. SLIs were college students who typically were not education majors. For some, this was their first time working with children. Therefore, SLIs received an intensive workshop regarding classroom management. Educators or other professionals in the field of education, who are also well versed in the CDFFS program, facilitated these workshops.

The Classroom Management workshop was one where SLIs were given the tools and strategies to run a well-managed classroom. Within the CDFFS program, participants learned the "Freedom Schools Way." This was a saying to describe the ways in which things were done in the confines of the Freedom Schools program. The management workshop described how discipline issues were handled in this "Freedom Schools Way." Participants were taken through a series of role-playing and scenarios to put into action the strategies presented. One particular approach was the "Island of Peace." This approach gave an alternative to time out. At Freedom Schools, isolating a student for negative behavior was not accepted. However, giving them an area to calm down and express their emotions in a positive manner was a practice. In the "Island of Peace" area of the classroom, students were given several options. They could read, draw, write a letter, or create something to explain the behavior exhibited and create a different way to react. The facilitators understood that not every strategy would work for every child; therefore, they also empowered the SLIs to create other management strategies that would fit their 
particular group of scholars. However, these strategies were required to be more about teaching and less about punitive punishments.

For whole group settings, SLIs and others in the program used a hand signal to gain the attention of participants. This technique required the leader or person seeking the attention of others to raise their hand. When this was done, it served as a signal to others to stop what they were doing, raise their hand, and give the person in charge their full attention. This was another classroom management technique used and taught to SLIs in the Freedom Schools program.

Lastly, the CDFFS program emphasized the importance relationships have on classroom management. SLIs were encouraged to build relationships with scholars that would ultimately assist in the management of their classrooms. It was emphasized that a scholar would not respond to directives unless they had a relationship with you. When they knew that someone cared, and were aware of his or her feelings, they would be more apt to follow the directives and instructions. The power of relationship building was a recurring theme in Freedom Schools.

During one of his interviews, Jacob commented that classroom management was a technique that he did not struggle with as a teacher. He said that others in the school often complimented him on his classroom management. When observing Jacob, situations arose within the classroom that required him to put his classroom management techniques to the test. When redirecting student behavior, Jacob used three distinct strategies: praise, the hand, and student conferences.

To get students to comply with his directive or expectation, he regularly praised students who were following directions the first time. Rather than focusing on the student who was misbehaving, he chose to praise the compliant student. This caused the other students to change 
their behavior so that they might receive praise from Jacob as well. Jacob used this strategy several times while being observed. Each time, students responded in the same manner.

Jacob also used the hand signal discussed previously to gain student attention. As soon as Jacob raised his hand, other students followed suit and within seconds, all students had hands raised and eyes on Jacob awaiting his directions or instructions. Jacob used this signal to regain focus following group activities where students were out of their seats and talking amongst themselves. Other times, Jacob would clap his hand in a certain rhythm in which students would immediately repeat the rhythm signaling his need for their attention.

Student conferences were a big part of Jacob's classroom management. They were used to redirect students who did not follow the previous directive or for students who committed major behavior offenses. For student conferences, Jacob temporarily removed the student, usually to the hallway, with the instruction to reflect on their actions. After a few minutes, Jacob met the student in the hall, discussed with him/her the behavior, and helped them develop a few options of appropriate behavior to use in case undesired behaviors arose again. During the conferences, Jacob's relationships with the students were evident through the conversations held. Jacob expressed that he usually has to conference with the same students on a regular basis. Therefore, he generally knew their thought processes and reasoning behind the behaviors shown. The influence of CDFFS classroom management techniques was seen throughout Jacob's classroom management techniques in his traditional classroom setting which showed a near transfer of classroom management strategies from CDFFS program to the traditional classroom. Although he made slight changes to fit his classroom dynamics, the Freedom Schools influence was seen and felt. In Freedom Schools, SLIs were taught to use the "Island of Peace" as a technique to give the scholar the time to reflect on their behavior and create a different 
response. Jacob used student conferences for a similar effect. The primary difference is Jacob made sure to take the time to conference with these students following their time of selfreflection. Furthermore, Jacob discussed the use of "I" statements during these conferences as a strategy he learned in a Freedom Schools classroom management workshop. His description of the experience is below:

I use a lot of "I" statements...I forget what training session this was, but they drove in "I" statements, "I," "I," "I." Make them feel like you're their friend almost. There's a thin line but make them feel like you believe in them. That's one of the things that stuck with me with Freedom School movement.

Jacob used the hand signal for the same purpose as its use in Freedom Schools. Lastly, Jacob showed near transfer of classroom management techniques through the use of relationships with his students as a means to get them to comply with his directives. During his interview, he discussed the influence Freedom Schools has on his classroom management in regards to relationship building.

I believe if you build a relationship first they're [students] more keen to listen to you, to get what you're trying to give them. I don't really yell. I don't yell at all because that's not how I was trained at Freedom Schools. We weren't trained to yell at students. I do have a natural calm demeanor, but I think Freedom School helped instill in me give them time to think, let them express themselves, and let them be expressive. They're all right. They're adults. They're mini adults. They can get made. They can get angry. I think Freedom School helped me do that. At Freedom Schools, you have plenty of opportunities to speak your mind and jump up and down and express yourself so why shouldn't I allow that inside of my realm of my classroom? 
Jacob credits much of his classroom management strategies to his time as an SLI and site coordinator (SC) in the Freedom Schools program.

Types of transfer. Of the types of transfer, Jacob most showed literal transfer which occurred in the use of CDFFS lesson organizational structure in the traditional classroom. Haskell (2001) described literal transfer as the use of knowledge or procedure directly in a new learning situation. Literal transfer can be seen as a form of near transfer.

The Integrated Reading Curriculum (IRC) has a definite organization of the lesson. The IRC began with an opening activity, led to the main activity, cooperative group activities (CGA), social action/conflict resolution activities, and closing activity. SLIs were required to write lesson plans based on the activities they chose for the day and then transfer those activities to a daily agenda that provided an outline of the day's lesson. The titles of the daily agenda were the portions of the lesson highlighted in the IRC. The purpose of the agenda was to provide the SLI and scholars an outline of what to expect for the day and to assist the SLI in staying on track during the lesson.

Jacob's daily agenda resembled a Freedom Schools agenda. The agenda used the same headings as an IRC daily agenda. Jacob referred to his activities as an opening activity, main activity, CGA, social action/conflict resolution activity, and closing activity. Jacob expressed that he looked at what objectives he needed to teach and changed the activities to fit into the organizational structure of an IRC lesson.

Jacob's use of an IRC structure in his traditional classroom lessons showed literal transfer in that his lesson structure mirrored a Freedom Schools lesson structure. Jacob stressed that the lesson structure he learned as an SLI is what he was most comfortable with and has helped him as a teacher the most. He stated, "I wouldn't be here and be a teacher without Freedom Schools I 
wouldn't be the teacher that I am. I might be a different teacher.” Jacob went on to discuss that his Freedom Schools experiences have stuck with him much more than his university teacher preparation program.

Participant 2 Faith

Level of transfer. Of the levels of transfer, Faith displayed near transfer. According to Haskell (2001), near transfer is the transfer of previous knowledge to new situations that are similar, but not identical, to a previous situation. Regularly, near transfer is seen in the transfer of procedures from one situation to another. It was determined that Faith's level of transfer, near transfer, occurred in three different domains: relationships with students, room arrangement, and classroom environment.

Relationships with students. The CDFFS program held relationship building at its core. SLIs were not only the leaders of the classroom but served as mentors for scholars. Therefore, it was essential that an SLI built relationships with the Scholars in the classroom and at the site as a whole. Relationship building took place at Freedom Schools in several means. However, open communication was a primary mean to building relationships. SLIs spent much of the day in meaningful conversation with scholars. Whether, during Harambee, lunch and breakfast times, IRC, or afternoon activities, SLIs were engaged in constant communication with scholars, serving as mentors and positive role models.

Faith emphasized the importance of building relationships with her students and allowing them to have a voice in her classroom. As a pre-kindergarten teacher, Faith found it imperative to build relationships with her students and gave them the space to show their budding personalities. Faith credits her Freedom Schools experience with understanding the importance of building relationships with students. She stated, 
Freedom Schools has helped me realize the importance of having those relationships with children. They're people, they have their own personalities and that's important as well as opening up and embracing their uniqueness. The beauty with Freedom Schools is whoever you are wherever you're from you can be a part of it. And it's very open to everyone's creativity, their learning styles especially. So that has helped me kind of remember, ok not everyone learns the same, their creativity is shown in different ways, and that's ok.

When visiting Faith's classroom, relationship building was witnessed through the conversations held with students. Throughout the day, Faith made sure to do a daily "check-in" with each student. During these "check-ins" Faith would talk with students about their day, family, or what they did the evening before. Although these conversations did not have an academic focus, the objectives were academic in that it promoted state speaking objectives and goals. Additionally, these conversations created a bond between Faith and her students. According to state objectives, these conversations can have any topic or focus, but Faith chose to use this time to create and strengthen relationships with her students.

Near transfer requires a participant to transfer knowledge between similar situations. Faith showed near transfer in the relationships she built with students through her acknowledgment of understanding the importance of relationship building from Freedom Schools and through the ways in which she built relationships with her students. The importance of relationship building is a concept usually taught in university teacher training; however, it was experienced in Freedom Schools. This experience gave the base knowledge of techniques for building relationships with students that Faith later transferred into the traditional classroom setting. 
Room arrangement and classroom environment. The CDFFS program required a very specific classroom arrangement that enhances the classroom environment. Every requirement of the classroom arrangement had a direct effect on the classroom environment. Two of the requirements of the classroom environment were the display of student artifacts and classroom theme.

Displaying student artifacts required SLIs to hang scholars' completed work on the walls of the classroom. As the weeks of Freedom Schools passed the amount of work, which covered the walls increased. The purpose of hanging student artifacts on the wall was to instill a sense of pride, accomplishment, and accountability in scholars. Scholars should take pride in having their masterpieces put on display for all to see. Naturally, this gave them a sense of accomplishment. Additionally, the display held students accountable to put their best foot forward. Since all work was put on display, scholars were encouraged and motivated to create the best work possible.

Each CDFFS classroom was required to have a classroom theme. The theme was one that exemplified what the class as a whole hoped to achieve throughout the summer program or the theme was whimsical and child-friendly. The theme chosen was not as important as the atmosphere it brought. Part of the classroom theme was the welcome door. On the classroom door, SLIs placed the name of each scholar of that class to welcome him or her to the classroom and let them know they belonged.

Faith's classroom walls were covered with current work. Students eagerly and easily pointed out their creations to any visitor who entered the room. Each student had, at least, one piece of material on the classroom walls. Additionally, Faith covered the walls with pictures of students. Their pictures were placed throughout the classroom for several purposes. Some pictures were snapshots hung around the room, other pictures were placed on top of student's 
work identifying the creator, and other pictures showed students participating in activities such as washing their hands placed above the sink. Finally, Faith's classroom door had a welcome sign with the name of each student attached. Although her classroom did not have a designated theme, a family like atmosphere was felt. The pictures of students hung on the wall and the personal conversations held with students led to the family like feel in the classroom.

The classroom environment and room arrangement unique to Freedom Schools was a contrast to traditional classroom settings. However, Faith used these techniques and altered them to fit her traditional classroom. This use of Freedom Schools techniques in a similar classroom setting showed near transfer.

Types of transfer. Of the types of transfer, Faith demonstrated procedural-to-procedural and literal transfer. Haskell (2001) describes procedural-to-procedural transfer as the use of procedures learned in one skill area transferred for use in another skill area. This type of transfer is also known as skill-to-skill transfer. It was determined that Faith's type of transfer, proceduralto-procedural transfer, occurred in two different domains: chants and cheers and the use of conflict resolution within the classroom. Faith was also aligned with the literal transfer that took place through the use of CDFFS pedagogical techniques in the traditional classroom. Haskell (2001) described literal transfer as the use of knowledge or procedure directly in a new learning situation. Literal transfer can be seen as a form of near transfer.

Chants and cheers. The CDFFS program had several cheers and chants that were recited throughout the day. The chants and cheers held a dual purpose, call and response skills and motivation. Call and response is a technique used in several cultures and settings for participant engagement. The same held true with Freedom Schools. The cheers and chants garnered scholar participation during Harambee. The nature of most of the cheers recited during Harambee was 
one of motivation. Freedom Schools used the words as affirmations over the scholars and the other participants. It was believed that what a scholar repeated to themselves with chants and cheers could eventually turn into their reality. Some Freedom Schools chants told scholars they were special, encouraged them to go to college, and motivated them to read books. Cheers and chants were not solely recited during Harambee; some cheers and chants welcomed scholars and visitors in the morning, praised them for a job well done, and to give direction.

Faith specifically used several Freedom Schools cheers and chants in her traditional classroom. She used the "Good Morning" chant to welcome students as they entered in the morning, the "Good Job" chant to give praise, and the "Take a Seat" chant to give directions. Faith and her students created additional cheers and chants that had an academic focus. These cheers and chants focused on simple addition, the alphabet, and colors. Faith's incorporation of the use of chants and cheers for repetition showed procedural-to-procedural transfer. Just as cheers and chants were used as affirmation in scholars at Freedom Schools, cheer and chants were used for academic focus in the classroom due to its use of repetition.

Conflict resolution. The IRC intentionally built in conflict resolution activities, when applicable to the story read, for a particular lesson. If the characters in the story were involved in a conflict, then it was guaranteed that a conflict resolution activity was included in the lesson plan. Conflict resolution activities placed scholars in the predicament of a conflict and taught them appropriate ways in which to resolve the conflict. The purpose behind these activities was to equip scholars throughout the summer with several techniques to make them conflict solvers. Conflict resolution activities offered a significant impact in the CDFFS program IRC. The techniques given through the IRC were echoed throughout the program. For example, if a student was involved in a conflict, the SLI may refer them to the previous conflict resolution activity as a 
means of solving their present conflict. A few conflict resolution skills taught in the IRC lessons created alternate responses when conflicts arose, role-played the right and wrong ways to handle a conflict, and taught scholars to be proactive and ways to acknowledge a potential conflict, and deescalating techniques for conflicts.

Faith offered her young students ways in which to solve conflicts. When a conflict arose, she required the students to come together, discuss the issue, and make amends. Additionally, she spoke to each student individually to have them express what they did to cause the conflict and ways in which they could have better handled the situation. Also, she had the students create a plan of action depicting ways to handle a similar conflict in the future.

Like Freedom Schools, Faith equipped her young students with conflict resolution strategies. She had them acknowledge the conflict, recognize their part in the conflict, think of ways they could have avoided the conflict, and ways in which they could handle future conflicts. Due to the young ages of her students, her conflict resolution strategies were not as in depth as many of the skills taught during IRC, but the concept and purpose were the same, depicting procedural-to-procedural transfer.

Pedagogical techniques. The CDFFS program was not a program for pre-service teachers. Many of the SLIs who participated in the program were not education majors nor had they ever previously worked with children. However, the CDFFS program offered several teaching and classroom management techniques to ensure that scholars received the best educational experience in their six weeks at Freedom Schools. These techniques were outlined in the IRC and SLIs were extensively trained on the correct use of these techniques during their weeklong training. The use of teaching aids such as a Venn diagram and web circle, along with the use of a reading circle were just two of the pedagogical techniques utilized in the Freedom 
Schools program. During the IRC lessons, SLIs used Venn diagrams and web circles. These charts were then hung around the classroom as anchor charts for reference in future lessons. The reading circle was the center of a Freedom Schools classroom. It is where scholars and SLIs sat to read the literature for the day and discussion. Allowing discussion to flow and place everyone on the same level was the primary purpose of the reading circle. While in the reading circle, the SLI was seated along with the scholars making eye contact. Because space was open, the expectation was that scholars and SLIs would remain open for discussion.

Faith used a reading circle in her classroom. When entering Faith's classroom, one would find her sitting in a circle on the floor with her students. Here she led the class in several activities. In the reading circle they read, participated in daily calendar activities, learned songs, reviewed material, heard directions, and participated in other activities throughout the day. Being in Faith's classroom, it was evident that the reading circle was the center of focus. Students knew to always return to the reading circle following any activity. Here students were open to their discussions and focused on Faith, especially when she delivered instructions. In the reading circle, Faith was able to see her room full of four-year-olds. No student was able to hide or get out of participating in the lesson. Faith also used Venn diagrams and web circles in her classroom. In one of the lessons observed, students used a Venn diagram to compare and contrast caterpillars and worms. Students were currently learning about the transformation that caterpillars made into butterflies and were reading a book on the topic. Previously, students learned about worms and the benefits they hold for the ecosystem. Around the classroom were anchor charts of web circles from previous lessons. One particular web circle covered the topic of worms, which Faith referred to during the present lesson. 
Venn diagrams, web circles, and reading circles are not techniques solely used by the CDFFS program, but in the field of education. However, Faith's use of these techniques came from her experience as an SLI in Freedom Schools. She stressed that she understood the importance of these techniques during her tenure in Freedom Schools. She also discussed that she often refers to what she knows from Freedom Schools when preparing her lessons.

Although Faith's use of Venn diagrams, web circles, and reading circles in her traditional classroom varied a little from their use in Freedom Schools, the use of these techniques was still deemed as literal transfer because she directly transferred these techniques from Freedom Schools into her traditional classroom setting. The use of these techniques varied little from their use in Freedom Schools. Faith chose to use the reading circle as the general meeting place for her classroom. Here she delivered many activities and was often the leader in the reading circle rather than the facilitator due to the age of her students. However, like Freedom Schools, Faith used the reading circle to allow open discussion and make eye contact with each student. Faith used the web circle and Venn diagram the same way as which she would use them as an SLI. However, the topics covered were not always from literature, but sometimes from other subjects such as science, math, and social studies.

Participant 3 Janet

Level of transfer. Of the levels of transfer, Janet indicated context transfer. Haskell (2001) describes context transfer as the transfer of knowledge within a different context. At this level of transfer, a person can apply prior knowledge within a different domain from where knowledge was initially gained. It was determined that Janet's level of transfer, context transfer, occurred in three different domains: relationships with students, pedagogical styles, and classroom environments. 
Relationships with students. Relationship building was at the core of the CDFFS program and was achieved several ways. The primary means of relationship building was through conversation. SLIs were required to sit with scholars during breakfast and lunch each day. While eating, they were encouraged to get to know and build relationships with scholars. This interaction between SLIs and scholars was not limited to eating times but throughout the day. SLIs did not have a designated break time scheduled in the day; therefore, it was expected that every minute of the day was spent with the scholars of the program. The SLIs were participants of the Integrated Reading Curriculum (IRC) lesson, Harambee, afternoon activities, field trips, etc. The constant interactions with scholars built genuine relationships.

The building of relationships was not geared solely towards the scholars, but towards the entire family. The CDFFS program required sites to hold weekly parent meetings and required parents to volunteer in the program. During parent meetings, various topics were explored, and many meetings were led by SLIs or other leaders in the program. At this time, SLIs were encouraged to get to know the scholar's entire village including parents and other family members. Additionally, the SLIs shared with parents their child's development and progress in the program, thus making the parent apart of their child's learning and Freedom Schools experience.

Janet placed an emphasis on building relationships with her students. She directly credited her experience in Freedom Schools as the reason in which building relationships was an important factor in her teaching. While observing Janet, the ways in which she built relationships with students was witnessed. Janet held several conversations with students throughout the day. These conversations typically had nothing to do with the curriculum, but with their personal lives. Throughout the observations, Janet was seen counseling a student about future college 
plans, helping a student heal from a broken heart, talking with a student who was having family issues, and discussing with another student the consequences of his actions in a different class. Students often stopped her in the hallways and her classroom to talk. Several of these students were former students. At lunchtime, Janet was on lunch duty located outside of the cafeteria. This post did not stop her from having lunch with her students. Several students who chose to eat their lunch outside of the cafeteria with Janet. During these times, they talked to her about various topics and sought her advice. The relationship she held with these students was evident in their confidence and the level of comfort they had with Janet.

Janet was not a native of the small city in which she worked. Therefore, she felt it critical to build relationships with not only the students but with the families. She discussed this as an obstacle in her interview, she stated,

Being that I'm not from here, I have to earn the trust of the students and the privilege of being a part of people's circle here. I've had to go the extra mile of making myself available, going to their [students'] games, being involved in the things they asked me to be there for. I feel like the best way to have an impact on my kids [students] is to have that relationship with them; to know the things that I'm doing for them is out of love and care.

Janet discussed the effort she put into the relationship built with parents. She called every student's parents each nine weeks to discuss grades and to get to know them. Janet also put on events in the evening where parents came to learn about the curriculum and to mingle.

Janet spoke about a student she and her husband was very involved. This student came from a broken family and had a mother who did not know how to get him to college. Janet and her husband attended several of this student's outside activities and even spoke with a college 
scout on behalf of his mother. Although she did not share this close of a relationship with all of her students, she was invested in each of them.

The ways in which Janet built relationships in the traditional classroom mirrored context transfer in that the same method of relationship building learned in Freedom Schools was transferred to the traditional class setting. Freedom Schools typically had a ratio of ten scholars to one SLI. However, Janet taught 70 plus students and was still able to build genuine relationships using techniques learned in Freedom Schools. Like Freedom Schools, Janet ate meals with her students and held honest conversations about their lives (not just curriculum) during these meals. In Freedom Schools, SLIs were required to participate in all activities with scholars throughout the day. Although work requirements hindered Janet from taking part in all activities with students throughout the day, she took the time to attend several of her students' outside extracurricular activities. Freedom Schools placed an emphasis on building relationships with parents and the families of scholars. As the required weekly meetings were held during Freedom Schools, Janet held parent nights to build relationships with parents. Additionally, she made contact with parents on a regular basis to enhance these relationships. The ways in which Janet built relationships with her students and their parents displayed a context level of transfer from practices learned in Freedom Schools to their use in the traditional classroom.

Pedagogical styles. The IRC served as the curriculum for the CDFFS program. To execute the curriculum, SLIs were extensively trained in several pedagogical techniques necessary to run a strong Freedom Schools class. Two of these styles were the use of small group instruction/cooperative group activities and reading circles.

With each lesson, the IRC specifically provided 3-4 small group activities, called cooperative group activities that promoted teamwork, hands-on activities, and the position of the 
SLI as the facilitator. Each day of Freedom Schools, students learned to work in these groups. The SLI stated group guidelines and gave a group role to each member. Each lesson required these groups to produce something tangible at the end of their lesson. Often the result was creative and artistic.

The reading circle was another pedagogical style emphasized in the IRC. Each Freedom Schools classroom was required to have a reading circle. Here a majority of the reading and group discussion, regarding the reading, took place. The importance of the reading circle was to provide a vehicle for group discussion to flow. Everyone was on one level, with the SLI sitting with the scholars, and all were looking at each other making eye contact.

Janet used both pedagogical styles while delivering lessons in her classroom. She credited her use and understanding of these techniques from her experience in Freedom Schools. She described this below,

They [the pedagogical techniques] are educational techniques, but I know the effects of these techniques because of Freedom Schools. Just all of those techniques, things that I think I've been taught in education, but seeing them and how they impact the way kids learn have come from Freedom Schools. Small group instruction, cooperative group activities, you know where they are actually doing something.

Each observation yielded itself to three different lessons with Janet and her students. During each lesson, students were required to work in small groups. While in these groups, they were responsible for creating and producing something original or artistic to demonstrate their understanding of the standard previously taught. During one particular lesson, students were reviewing for an upcoming test. Janet created a game in which students would work with their groups to answer the questions, but come up with a non-traditional explanation to support their 
answer. Each group had to answer each question. She evaluated the students and gave a group points based on correct answers and level of creativeness. Each group member had a particular role and was encouraged to stick to those roles throughout the entire lesson.

During two of the lessons observed, Janet used reading circles. It was evident that students had used this technique several times showing a familiarity with the circle and the expectations for reading within a reading circle. Due to the number of students in her classes, Janet had several reading circles. Each circle used a different reading style based on students' reading levels. Janet floated between the circles reading and discussing the literature.

The pedagogical techniques taught in the CDFFS program and the use of these forms in Janet's classroom displayed context transfer in that the same educational methods employed in Freedom Schools were used in a similar context by Janet in the traditional classroom. Janet used cooperative group activities in her classroom to show mastery of a standard in a similar way that SLIs used cooperative group activities to show knowledge of the literature read within a lesson. Additionally, the group roles in which Janet used in her classroom were the same roles used in a Freedom Schools classroom. Additionally, Janet's use of cooperative group activities placed her as the facilitator and gave students the opportunity to work with and learn from their peers. This was the goal of cooperative group activities in a Freedom Schools program.

Like a CDFFS program classroom, Janet's class frequently used reading circles. Although Janet used multiple reading circles due to the size of her class, she used them for the same purpose as SLIs in a Freedom Schools classroom. The reading circle was used to place everyone on the same level, establish eye contact among participants, and offered a vehicle for discussion to flow easily. The use of cooperative group activities and reading circles in her 
classroom displayed a context level of transfer from pedagogical styles learned in Freedom Schools to their use in Janet's traditional classroom.

Classroom environment. The CDFFS program required a very specific classroom environment. SLIs were trained and evaluated on the setup requirements of their classroom environment. Three of the requirements of the classroom environment were the display of student artifacts, teaching aids, and the use of workstations.

Each Freedom Schools class displayed scholar artifacts around the classroom. As scholars completed activities, the expectation was that the SLI promptly posted the scholar's work for all to see. This was to instill pride in the scholars and to show appreciation for the work they had created. As the time in Freedom Schools progressed, the classroom became a living museum of scholarly work plastered around the room. Along with displays of academic work, were teaching aids that enhanced previous IRC lessons. Particularly the teaching aids of web charts, Venn diagrams, and KWL charts. The use of these charts was specifically stated within the IRC. SLIs were trained on the use and implementation of these charts to guarantee they are used correctly. The completed charts were hung on display as an anchor chart for future lessons.

The CDFFS classroom environment required a designated area for workstations. In these areas, scholars completed cooperative group activities. The stations were formed to encourage group work. They usually consisted of tables or desks organized in such a manner that scholars could work together. This area was labeled and standard within a Freedom Schools classroom.

Janet used the three described components of the CDFFS classroom environment in her traditional class. Janet's classroom walls were covered with student work. She posted an artifact from all students. The artifacts were not just limited to schoolwork, but to pictures of students, poems written, and newspaper clippings. She also used student vernacular as her titles for the 
groupings of artifacts. For example, she had a bulletin of inspirational quotes written by students with the title of "Truk Da Wurl" which stemmed from a popular hip-hop song and translated to "Take over the world." Additionally, Janet had several teaching aids from previous lessons hung around her classroom. The teaching aids included Venn diagrams, word webs, and KWL charts. In one lesson observed, Janet used a KWL chart to introduce the topic to be discussed. Janet grouped her students together in groups of four. Within these groups, students completed cooperative group activities. Janet described the classroom makeup as one that makes group work more feasible than a classroom that has desks and chairs in straight rows. Students used the classroom seating arrangement to talk with their peers about the assignments given and discuss the current topic.

The classroom environment unique to the CDFFS program and the use of these components of the environment in Janet's classroom displayed context transfer in that the same components of the classroom environment employed in Freedom Schools were used in a similar context by Janet in the traditional classroom. Like a Freedom Schools classroom, Janet's classroom was a living museum of student artifacts. Students work was front and center for all who enter the class. Although she was unable to plaster all student work on the walls due to the number of students on her rosters, she did make an effort to depict at least one artifact of each student. Janet used the same teaching aids in her classroom that she learned as an SLI in Freedom Schools. There were several KWL charts, Venn diagrams, and web charts displayed as anchor charts around the classroom. Finally, Janet placed her students in groups of four to encourage group work. Due to the number of students in her classes, she was unable to make a separate area that is labeled workstations, but she did use the desk grouping for the same purpose that SLIs used workstations in Freedom Schools. The extent to which Janet displayed student 
artifacts, used teaching aids, and workstations in her classroom demonstrated a context level of transfer from the classroom environment required in Freedom Schools to their use in Janet's traditional classroom.

Types of transfer. Of the types of transfer, Janet connected with conditional transfer. Haskell (2001) described conditional transfer as the knowledge learned in one context that can be transferred to another context. Additionally, this type of transfer required the knowledge concerning when to apply the learned knowledge to a different context. It was determined that Janet's type of transfer, conditional transfer, occurred in two different domains: lessons plans and the level of encouragement and recognition given to students.

Lesson plans. The IRC served as the official curriculum of the CDFFS program. Each year, a group of highly qualified educators and scholars came together to create a book of lesson plans to be used the following summer. These lesson plans served as the systematic guide based on the portion of the book read each day. Each lesson plan had several components, opening activity, main activity, cooperative group activities, social action/conflict resolution activity, and closing activity. SLIs were extensively trained to present the IRC to scholars. The books read in the CDFFS program varied each year on a four-year cycle. Meaning every four years a book was repeated in the curriculum.

Janet declared that she regularly used Freedom Schools materials in her classroom. Observations backed up her claim. During one observation, the researcher witnessed Janet following the lesson plan from the CDFFS IRC curriculum book for the novel Monster by Walter Dean Myers (199). Over the course of several days (the observation came in on day three of the lesson plan), Janet took her students through the systematic lesson of the IRC curriculum. During observation, students completed a cooperative group activity in which students created an 
argument on behalf of the central character to later present in a mock trial. Additionally, Janet's daily agenda depicted the components of the IRC curriculum as broken down in her lesson.

The IRC curriculum book presented a systematic process for the delivering a lesson due to the amount of SLIs who were not certified teachers or in a teacher preparation program. Therefore, it was necessary to offer a detailed and systematic approach to delivering the lesson. Although Janet is a certified and university prepared teacher, she was able to implement the Freedom Schools lesson into her traditional classroom. Based on observation, the inclusion of this lesson plan was a success. Eighteen out of twenty students were engaged; students delivered powerful arguments, and were able to recall information learned throughout the lesson during a quick review at the end of the class period. The knowledge Janet had of when and how to apply a CDFFS IRC lesson into a traditional classroom supported Janet's conditional transfer of Freedom Schools practices into the traditional classroom.

Encouragement and recognition. The overarching theme of the CDFFS program was "I can make a difference." The CDFFS program sought to empower scholars with the understanding that change began with them. Through this process, scholars were encouraged and uplifted throughout their time at the program. Much of this encouragement took place during the morning gathering referred to as Harambee. During Harambee, scholars sang the motivational song, Something Inside so Strong by Labi Siffre (1990), and received and gave recognitions. The lyrics to the motivational song delivered a message of hope and strength. It relayed to the scholars that no matter what obstacle they were facing they would make it because of the power that lies within them. All participants in the Freedom Schools program sang it daily. Recognitions were a time to celebrate scholars. Scholars were recognized by SLIs or by other 
scholars for having excellent character. They were recognized for the kind and generous acts witnessed.

During an interview, Janet described her use of motivational songs within her classroom. She allowed the students to choose a motivational song on a weekly basis. This song was played throughout the class while students were working on activities. Janet also gave recognitions at the beginning of each class. During an observation, Janet began the class by telling the story of a student who played in a football game the previous evening. She congratulated him on his success of scoring several points. The class joined in with Janet in congratulating the student on his success. Once this recognition was done, she began her lesson.

Recognizing students for their accomplishments is nothing new to education. However, Janet's use of encouragement and recognition in her classroom was transferred from her Freedom Schools experience. This transfer was not only discussed through her interviews but also witnessed during classroom observations. Although she made changes to the motivational song and recognitions to fit her traditional classroom, the conditional transfer of these two techniques was evident through her knowledge base of the purpose of recognition and encouragement in Freedom Schools to her application of these practices in her current classroom.

\section{Comparison of Findings}

The level of transfer between each participant varied. It was concluded that this is due to a number of years and the levels of participation each one has in Freedom Schools. For example, Janet had been involved in Freedom Schools for the longest time and in the most capacities, while Jacob had been involved with the program in the least number of capacities. A cross analysis of the findings examined each participant's experience in Freedom Schools in regards to 
their level of transfer followed by an analysis of the practices as they pertain to Culturally Relevant Pedagogy (CRP).

Janet had been a part of Freedom Schools for many years. She began the program in elementary school and was a scholar for nine years. In all, she has been a part of the CDFFS program, in some capacity, for 23 years serving in the capacities of a scholar, junior SLI, SLI, site coordinator (SC), and an Ella Baker Trainer (EBT). Consequently, she showed a higher-level of transfer than the other two participants. It was concluded that this was due to her extensive involvement in the CDFFS program. Janet credited this extensive experience in Freedom Schools as the reason she used many Freedom Schools techniques in her classroom. She stated, 'I've been the scholar, and I've been the teacher, so I know the effects that Freedom Schools has on the scholar and the effect it has on the classroom culture." It was logical that Janet showed the highest levels and types of transfer due to her understanding of the effects on both sides as the scholar and the SLI or teacher.

Faith's years of participation in Freedom Schools and the capacities in which she has were less than Janet's years of service. Faith served as an SLI, SC, and an EBT. As an EBT, Faith was responsible for serving on a team of trainers who lead the official CDFFS program national training. Therefore, it was expected that she would be an expert in Freedom Schools particularly the IRC. This expertise was shown in her transfer of pedagogical styles from Freedom Schools into the traditional classroom. The amount of additional training EBTs received in the IRC to train others made these pedagogical techniques and styles deeply ingrained in these individuals. As a result, these techniques and styles were readily apparent in Faith's traditional classroom setting. 
Although Jacob and Faith have the same number of years in the Freedom Schools program, Jacob's involvement in the Freedom Schools program was not as intense as Faith's. He served as an SLI and an SC. Therefore, it was anticipated that he would not have as high of a level of transfer as the other participants. However, it was evident that the time in which Jacob spent in Freedom Schools as an SC transferred into his traditional classroom setting. As an SC, Jacob was responsible for managing the site including SLIs and scholars. Often times he was responsible for managing behavior. The transfer observed in his classroom was higher in his classroom management strategies rather than his pedagogical strategies.

Not only did the findings depict the transfer of instructional practices, but the findings illustrated the use of CRP within the classroom. The instructional practices that were transferred from Freedoms Schools were practices that depict CRP. For example, Jacob's use of studentteacher conferences as a form of classroom management embodied CRP by having the student accept responsibility and have hard conversations. The conferences required the student to take responsibility for their actions. Moreover, the student was not allowed to shy away from this difficult conversation but was required to acknowledge their wrongs head on. Consequently, a student was also permitted to advocate for themselves during these conferences if they felt as though they were falsely accused. This CRP way of classroom management gave the student equal power in the consequences given for their actions. They were able to give their input on what consequence was acceptable for the action.

The relationships Faith built with her young students displayed CRP through acknowledging these students as the people that they were. Faith stressed the importance of giving these students a voice and helping them to discover who they were. This was crucial to 
Faith because she hoped that this would provide them with a solid foundation and build their confidence.

Janet made a conscious effort to incorporate her students in every aspect of her teaching including the classroom environment. Janet's incorporation of her students in the classroom environment through the display of their work, use of student vernacular throughout the classroom, and daily recognition of student accomplishments all exhibited CRP. These pedagogies created a family environment in her classroom that attempted to make each student feel welcomed and apart.

\section{Summary}

Chapter four examined the teachers' individual results of the observations, interviews, and level of transfer. The individual responses were then combined to analyze for similarities and differences to serve as cumulative results for the group. The differences amongst the three teachers were based on the amount of time and the entity in which the teachers served in Freedom Schools as compared to their level of transfer the domain in which the transfer occurred. In chapter 5 , these time differentials are applied to the assumptions provided by Haskell. The findings concluded that even with extensive experience or a significant amount of time spent in Freedom Schools, transfer of instructional practices from Freedom Schools to the traditional classroom was still low by transfer standards. 


\section{CHAPTER 5}

\section{IMPLICATIONS}

\section{Purpose}

The purpose of the study was to investigate the transfer of instructional practices from the Children's Defense Fund Freedom Schools (CDFFS) program to the regular classroom by teachers who served as servant leader interns (SLIs) in the Freedom Schools program.

\section{Research Questions}

1. What levels of Freedom Schools instructional practices are transferred into traditional classrooms, as observed among former Freedom Schools Servant Leader Interns (SLIs) who are current classroom teachers?

2. What practices, gleaned from SLI experiences, do K-12 teachers report, who served as SLIs, name as influential experiences in their teaching practice gleaned from the Freedom Schools program?

3. What evidence is there that specific types of transfer occur through the Freedom Schools practices in use in the current classrooms of SLIs?

\section{Transfer of learning assumptions}

According to Haskell (2001), transfer has a higher potential of occurring when the 11 principles are applied. The assumptions for this study are based on the status of the application of these principles during the CDFFS preparation program. What follows is an examination of the principles within the context of the CDFFS pedagogical practices witnessed in the participants' classrooms and interviews conducted. The overarching assumption is that adherence to the 11 principles enhances the probability that transfer will occur at a high level in other instructional settings. 


\section{Acquire a large primary knowledge base in the area in which transfer is required.}

Learners must possess a large primary knowledge base in the content area requiring transfer (Haskell, 2001). However, simply maintaining a knowledge base is insufficient. In addition to possessing a knowledge base, one must possess thinking and reasoning because transfer requires that learning is transformed into a basic form. One must incorporate a concept or principle "so thoroughly into one's cognitive system that it becomes a part of one's personality" (p.116).

The assumption for principle one is an acquisition of a large primary knowledge base of the Freedom Schools pedagogical practices would lead to transfer. As stated in chapter one, those who served as SLIs in the Freedom Schools program were required to attend an extensive weeklong training each year while in the program. Additionally, participants were exposed to two additional trainings at their individual CDFFS sites.

Each participant showed a large primary knowledge base of CDFFS pedagogical practices as evident in the length of their Freedom Schools experience, interviews, and observations. However, results of the study showed that the level of transfer observed in the regular classrooms, related directly to the length of time of involvement in the CDFFS. The implication for acquisition of a large body of knowledge is demonstrated in longevity and continuous participation in CDFFS.

Janet and Faith both showed moderate levels of transfer of pedagogical techniques from Freedom Schools to the traditional classroom. Both participants served as Ella Baker Trainers (EBTs) for Freedom Schools. EBTs participated in numerous hours of training each year in the IRC for purposes of teaching SLIs who attended the national training in the IRC. Therefore, Janet and Faith are deemed as the "experts" of the IRC. This expertise was evident by IRC 
instructional strategies viewed in their classrooms. Both Faith and Janet expressed the naturalness they felt in using these techniques in the traditional classrooms. However, use of CDFFS pedagogical techniques was not apparent into every aspect of their teaching, hence the moderate level of transfer designation.

Jacob spent three years as a site coordinator in the CDFFS program. The site coordinator (SC) was the person who supervised the program on a daily basis. One of the responsibilities of an SC was to handle disciplinary issues that were too large for the SLI to manage. Jacob's level of transfer for principle one was a low-level pedagogical transfer, but a higher level of transfer in regards to classroom management done the "Freedom Schools Way". Jacob transferred many classroom management techniques into his classroom. However, not all of his management strategies were from Freedom Schools. According to Jacob, some strategies developed from teaching experience. The assumption that a primary knowledge base was necessary for transfer to occur was sustained. However, a high level of transfer was not evident.

\section{Acquire some level of knowledge base in subjects outside the primary area.}

Haskell argues that for adequate transfer to take place, a large knowledge base is required. Conversely, a broad knowledge base alone will not learn transfer; it is necessary for one to learn a large amount of outside knowledge to have an adequate knowledge base in the primary area.

The assumption for principle two noted that because Freedom Schools is a unique program with norms that extend outside of the typical expectations of a traditional school and other summer literacy programs, those who participate are exposed to very few outside subject areas that provide additional knowledge base of Freedom Schools' practices. 
Although each participant matriculated through a university teacher preparation program, the skills gained from the university preparation program were not definitive or elaborate enough to ensure transfer of the concepts outside of the primary knowledge base. This principle was not applied, and therefore not transferred.

\section{Understand what transfer of learning is and how it works.}

Transfer is conducive to all levels of learning, ranging from low-level skills to high-level theoretical thinking, therefore; learners must grasp the nature and function of transfer (Haskell, 2001). As a process, transfer enables our past knowledge to impact our ongoing learning. Since transfer influences all learning, memory, problem solving, and cognitive processes, it is imperative that learners understand what transfer of learning is and how it works.

The Freedom Schools national training institute did not focus on giving SLIs the tools to transfer the knowledge gained from Freedom Schools to the traditional classroom or into any other professional area. However, participants in this study did show levels of transfer from Freedom Schools into their regular classroom through pedagogical practices. Still, the levels were low levels of transfer. According to Haskell (2001), this was a result of the participants not having knowledge of transfer of learning and how it works. In this case, Freedom Schools does not equip participants with the knowledge of using ideas and skills gained in Freedom Schools in

other areas. As a result, transfer was minimized due to the lack of application of this principle in the Freedom Schools pedagogical training.

\section{Understand the history in the area(s) that transfer is wanted.}

Haskell argues that the knowledge of history is a basis of transfer of learning. To transfer learning, you must have an understanding of the events that have happened previously. 
For this principle, it was assumed that receiving a vast amount of historical background knowledge in Freedom Schools educational history along with the familiarity of general education history learned in teacher preparation programs would combine and transfer to pedagogical practices in the classroom.

Although, Freedom Schools participants receive an extensive amount of facts regarding the historical timeline of the American Civil Rights era including the creation of Freedom Schools, a historical timeline of education within America as a whole was not emphasized during Freedom Schools training of SLIs. However, it was anticipated that those who enter the teaching profession have taken courses that discuss the historical context of American education.

Neither the history of Freedom Schools nor the history of American Education was ever mentioned by the participants or observed as the basis of their pedagogical practices. Therefore, the assumption that receiving a vast amount of historical background in Freedom Schools educational history would transfer to general education was not enough to translate into the transfer of pedagogical practices was sustained.

\section{Acquire motivation, or more specifically, a "spirit of transfer".}

Haskell (2001) suggests the "spirit of transfer" represents the passion that one has for what they do, be it research, learning, or teaching, when one is passionate, that passion stems from them and produces greater results.

Individuals who participated in Freedom Schools typically have a great passion and love for the program. This passion stems from the love of the program, but more importantly from the observed positive effect on the students in the program. It was assumed that this spirit was carried into the teaching careers of those who became teachers. 
Each participant stressed the love and admiration for the program. Although each participant loved Freedom Schools, this love did not cause a high-level "spirit of transfer'. Regardless of his or her amount of admiration for the program, no participant showed a high level of transfer, based on love. It was expected that participants would carry the energy emphasized in Freedom Schools into their classrooms as it transfers from the national training institute into the Freedom Schools sites. This included the use of chants and cheers, recognitions, motivational songs. Although each participant included one of these aspects into their classroom, the energy in which the aspect looks and feels like at a Freedom Schools site was not felt or seen. The levels of transfer were low levels, therefore; the assumption was not met since the "spirit of transfer" was exhibited in the form of lower levels of transfer.

\section{Develop an orientation to think and encode learning in transfer terms.}

All learning takes place in a particular context. The context in which learning takes place determines whether one will be able to transfer that knowledge when necessary. Haskell argues the "largest breach of context concerns learning in the classroom versus the everyday world" (p.140); this is one of the major failures of K-12 education. Often, students are not able to transfer the knowledge learned in the classroom to everyday experiences. Students must learn to encode this knowledge so that it may be transferred when needed.

The likelihood of transfer to occur was minimal at best. Freedom School takes place during a 6-week period with emphasis on being a non-traditional classroom setting. Lessons are presented in engaging ways; the site is full of cheers, chants, and songs; student are encouraged to express themselves in ways unique to their personalities; classrooms are a 1:10 ration of SLI to scholars; and there is no high stakes test at the end of the summer. However, students in 
traditional schools are faced with high stakes tests, classrooms of thirty or more students, and teachers who feel pressure from administration.

Participants showed mid-levels of transfer in regards to the knowledge gained in Freedom Schools transferred into traditional classroom settings. Each participant transferred certain techniques and pedagogies into their classroom. However, the levels of transfer were not consistent nor of high levels across the board. Although transfer was seen, the minimal level of transfer supported the assumption that the likelihood of transfer would be minimized.

\section{Create cultures of transfer or support systems.}

Transferring knowledge does not always come naturally for students. They must be surrounded by a culture that supports transfer. This culture is one that acknowledges transfer and supports it throughout the learning process. Haskell suggests that those who receive on the job training have built-in culture of transfer and a support system. As the cultures developed within workplaces, this similar culture must be built into institutions of learning for successful and longterm transfer to take place.

SLIs received weeklong training and on the site training throughout the summer. However, transfer of the knowledge from Freedom Schools to the traditional classroom was not the goal of this training. There was no teacher development training or support for SLIs who chose to teach as a career path. Therefore, it was assumed that transfer would be minimized as a result.

Participants did not receive any support in transferring Freedom Schools pedagogies into the classroom. The transfer that was made came from the amount of experience and the depth in which they served in the Freedom Schools program. Even the participant with the longest amount of time of service in Freedom Schools showed low-level transfer overall. The lack of 
creation of a culture of support was apparent in the lack of transfer from Freedom Schools to the classrooms.

\section{Understand the theory underlying the area(s) in which we want to see transfer.}

Haskell discusses the need for one to understand the theory that underlies the area in which they want to see the transfer. Without certain theoretical knowledge, we would not understand the knowledge to make a successful transfer. Haskell argues that many transfers are made unsuccessful due to the lack of knowledge of theory that underlies the information where transfer is sought.

Those who matriculate through a traditional College of Education certification program are taught several educational theories before the completion of a program. However, those who chose the alternate route, often miss this information. Each of the participants in the study was a product of a university teacher preparation program. Therefore, each participant received, at least, one semester of coursework in educational theories. Freedom Schools does incorporate "best practices" into its curriculum and class setup, but there was no evidence of theoretical teachings within the Freedom Schools Integrated Reading Curriculum (IRC) or the training in any of the observations or interviews. During interviews, no participant discussed educational theory as the foundation of their theoretical practices. Ultimately, the assumption that participants who matriculated through a university teacher preparation program are well versed in education theory that would assist in their transfer of Freedom Schools practices to traditional classroom setting was not enough to translate into the transfer of pedagogical practices was sustained. 


\section{Engage in hours of practice and drill.}

Haskell argues that practice and drill are necessary to build a solid knowledge base upon which transfer of learning can occur. He stresses that he does not approve of the drill and kill as seen in school houses where "methods of rote memorization and mindlessly drilling students in their lessons of readin' writin' and 'rithemetic" (p.171) were the norm, but he encourages reflective practice. Schon (1983) defines reflective practice as "the capacity to reflect on action so as to engage in a process of continuous learning" (p.102). When one is reflective in their practice, they are then able to build a solid knowledge base where adequate transfer can occur.

SLIs received a significant amount of practice on the information they were given during the Ella Baker Child Policy Training Institute. If a person was an SLI for more than one year, they received training every year at a deeper level. This equated to hours of practice and drill of the pedagogical strategies practiced in Freedom Schools. It is, therefore, assumed that these practices would transfer outside of Freedom Schools and into the traditional classrooms.

The participants attended Freedom Schools training from six to ten times. They each had an extensive knowledge of Freedom Schools and hours of drill in Freedom Schools practices. The Freedom Schools practices taught during national training were evident in each person's classroom but at low levels. The strategies and the amount of strategies transferred did not reflect the amount of hours of practice these participants had in Freedom Schools. Therefore, the assumption that the practices would transfer is upheld, but in low levels of transfer.

\section{Allow time for the learning to incubate.}

Haskell suggests that learners have adequate time to think and ponder about new information for learning to take place. SLIs participated in many self-reflective assignments and activities. These activities were intended to assist SLIs in understanding their purpose for serving 
in Freedom Schools and to evaluate their practice as servant leaders. It was assumed that this practice of self-reflection would be transferred for those who choose to teach as a career.

Due to the positions held in Freedom Schools, each participant participated in and led numerous debriefing sessions that allowed time for self-reflection. However, only one participant, Janet, mentioned transferring the use of self-reflection as a regular teaching practice. The other participants never mentioned using the practice nor was the practice observed. The low level of transfer amongst the participants negates the assumption that the practice of selfreflection was transferred.

11. Observe and read the works of people who are exemplars and masters of transfer thinking.

According to Haskell (2001), it is crucial that learners read and observe exemplary works of transfer thinking. Reading the works of great exemplars of transfer thinking is important because it provides readers with first-hand knowledge of how critical a role reasoning has played in history's greatest discoveries, inventions, and innovations.

It was assumed that transfer from Freedom Schools to regular classroom teaching would be limited because principle 11 is not directly applied. As stated earlier, the Freedom Schools program did not make transfer of practices from Freedom Schools into other settings its focus. Therefore, it was not necessary for SLIs and SCs to read the works of people who are masters of transfer. Participants were not aware of transfer of learning nor of the people who are masters of transfer thinking. Many participants referred to their former teachers as "masters" of education rather than noted theorists or figures in the field of education. It is through discussions and observations of these "masters" that they first understood a notion of teaching. However, this did not uphold the transfer of Freedom Schools practices to traditional classroom settings, thus sustaining the assumption that low to no level of transfer would occur regarding this principle. 
In summary, the levels of transfer were low due to the lack of implementation of the 11 transfer principles. The CDFFS program did not apply the 11 principles of transfer during the national training institute or subsequent trainings. Consequently, it was logical to expect low transfer or no transfer at all. Meaning that for SLIs to transfer instructional practices at high levels, it was imperative that participants understand transfer and that the CDFFS program implement this idea in the training. This study demonstrated support for the suppositions of Haskell's Theory of Transfer. The limited application of the principles of transfer resulted in limited and low levels of transfer.

Although the levels of transfer were low in regards to Haskell's standards of transfer, there were several CDFFS instructional practices observed in the traditional classroom settings as described in chapter four and the assumption in chapter five. These instructional practices mirror CRP practices discussed in chapter two. According to the research, teachers who embody CRP are teachers who build relationships with their students, create a family environment, and offer students a place to belong, have high expectations, and empower students. The participants in this study personified these characteristics of CRP as seen in their use of CDFFS instructional practices.

\section{Implications for future research}

The primary focus of the CDFFS program is to "to build strong, literate, and empowered children prepared to make a difference in themselves, their families, communities, nation, and the world today" (Children's Defense Fund, 2016). This study focused on the effect that the CDFFS program had on SLIs who eventually entered the teaching field in regards to transfer of learning of Freedom Schools practices on classroom teaching practices. The findings from the study verified that when the principles of transfer were applied, initial levels of transfer were 
observed. A more direct adherence to all transfer principles could potentially increase transfer to higher levels and types. Hence, if the CDFFS program, in the future, seeks to train potential teachers, more transfer principles must be adhered to during the training of SLIs. A study of the implementation of more principles during the SLI training institute and the effect on transfer levels and types would strengthen the overall program.

Increased application of the 11 principles of transfer could potentially have implications for children's reading habits as self-empowered scholars. The focus of the Freedom Schools program is children and their development as scholars. The intent is that when children leave a Freedom Schools site and enter into the traditional classroom setting, they will be ready to transfer their learning at a high level. There is a lack of evidence of whether or not the love of reading and empowerment that Freedom Schools prides itself on instilling in children, carries on outside of the confines of the Freedom Schools program. A study of transfer of learning among children who participated in Freedom Schools, to their learning in traditional classroom settings, would strengthen the understanding of whether the Freedom school approach to reading enhancement transfers to regular classroom settings.

The final recommendation is a replicative study of other SLIs who entered the teaching field post SLI experience. The CDFFS program could put its resources into studying the transferability of Freedom Schools practices into classroom practices. By studying these teachers and rating what level of Freedom Schools strategies are used in classrooms, the program can use these data to strengthen the need for Freedom Schools, not just for the children, but for future educators.

There were three limitations to this study: participants, time, and bias. The small group of participants did not represent the number of SLIs who have chosen teaching as a career. 
Additionally, the participants have varied years of teaching, which limits the understanding of what transferred from the Freedom Schools program and what has been learned simply through full-time experience. A replicative study of SLIs who have similar experience in Freedom Schools and their experience as a traditional classroom teacher may better evaluate the transfer of learning from Freedom Schools into the traditional classroom. Due to my experience in Freedom Schools, I have an extensive background knowledge of the program and the expectations. Although all attempts were made to remove any bias, there is still some bias due to my extensive background knowledge and great love of the program. A duplicate study by someone who does not have experience with the CDFFS program may be better suited to identify true teaching strategies that are solely unique to the Freedom Schools program and observable in classrooms.

Finally, a small amount of instructional practice was examined, limiting the ability to observe a complete picture of the teachers' practices. Future research that can observe the teaching practices of a teacher over a longer time span may give a better assessment of transfer of learning from Freedom Schools to the traditional classroom setting.

\section{Conclusion}

The CDFFS program is a unique 6-week summer program that focused on changing the lives of children through literature and empowerment. The children who participated in the program are not the only ones who are forever changed. SLIs who went through the Freedom Schools program took with them different aspects of the program throughout the rest of their lives. As seen in this study, SLIs who later entered the teaching career transferred some instructional strategies from Freedom Schools into their traditional classroom. However, the levels of their transfer were low due to the lack of implementation of the 11 transfer principles. 
This study revealed that for SLIs to transfer instructional practices at high levels, it is imperative that the understanding of transfer, the application of transfer, and reflection on transfer are implemented. If transfer is a goal, the CDFFS program should consider implementing transfer of learning theory in future SLI training. 
APPENDIX A

\section{INTERVIEW QUESTIONS}


Interview I

1. Tell me about your experiences in school from as far back as you can remember until the present day.

2. Who do you consider to be your most influential teacher? What made his/her teaching styles so special to you?

3. When you look back at your educational experiences, are they positive or negative experiences? Why?

4. What would you say led you into the teaching profession?

5. How did you become affiliated with Freedom Schools?

6. Describe your Freedom Schools experience.

Interview II

1. Tell me about your typical day as a teacher. Begin with the time you wake up until you fall asleep.

2. How do you describe your relationships with your students? Other faculty? Parents? Admin? Community?

Interview III

1. Given what you have said about your life before you became a teacher and given what you have said about your work now, how do you understand the effect of experience in your life? What sense do these experiences make to you?

2. Now think about the Freedom Schools experience that you described, how has that experience impacted your teaching?

3. Given what you have reconstructed in these interviews, where do you see yourself going in the future?

4. Is there anything you'd like to share that I haven't asked you in this interview? 
APPENDIX B

\section{QUESTIONNAIRE}


Name:

Age: ___ Gender: ___ Race/Ethnicity:

Number of years that you have participated in the Children's Defense Fund Freedom Schools

Program:

Positions held in the Children's Defense Fund Freedom Schools Program (please check all that apply)

Scholar

Servant Leader Intern

_ Site Coordinator

Project Director

Executive Director

Ella Baker Trainer

Consultant

Volunteer

National Staff

How many years have you been a classroom teacher?

What grade and subject(s) do you currently teach?

What grades and subject(s) have you previously taught? 
APPENDIX C

OBSERVATION PROTOCOL 


\section{Freedom School Pedagogies Teacher Observation Record}

Teacher

School Grade Level/Subject

Dabe of Observation:

Time of Observation

Total $f$ of students present

Obeerve the criteria listed in each of the six categorles below. Check each criterion that the teacher demonstrates the majority of the lesson or obeervation period. Provide specific comments and feectbeck for clarity.

1. Clagaroom Emvironment

Check if teocher demongtrates the criterion for the malority of the obecrvation

Sudant work and artlacts are dsplayed

Teacting aibes enharice the lesson

Teacting aides are feat, compeling. and grammatically conted

Usiens mark stations and supplien appispiately

Exabishes a phraicaly and emodenally irwiting dimarson

\begin{tabular}{|c|}
\hline Comments: \\
\hline
\end{tabular}

2. Approsachea in inatnuction

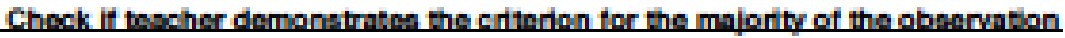

Introducas the lesson and objectives eflectuely

Salmulates inberme in the focus skatopke

Uses graphic arganibars effectivaly

Uses appropriete actubles to estebinh the inson's focus

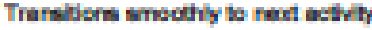

Ratively pertipabes dufing the lesson

Maribers the Eime of each eamponert of the lesson

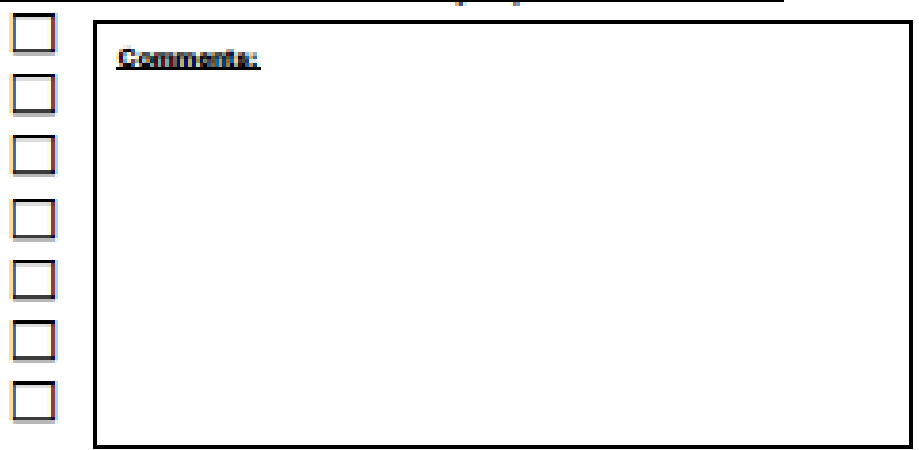

3. Culturelly Restevant Curriculum a Wotediale

Uses culturally releremt beoks and resoutcen

Understandwluses speech and expiesvions farmilia to studerns

Unes curficular materials that represents a variaty of perpectives

Ineorperates scuderts' eutures, femiles and communites into lesson

Demorstrabs mutud and genuine inspect for eshural dvarily

Demoristabs krowledge of muliple aspects of dvernily

(e.g. ethrichy, languege, sceid cless, ieligion)

Uses cultural exarnpies and mataphors to cannect concepts to sudents" prier knowledge

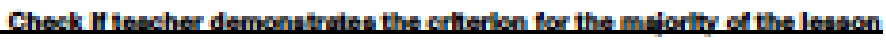

Cemmente: 
Lesson objectivefocus sxill is dearty evident

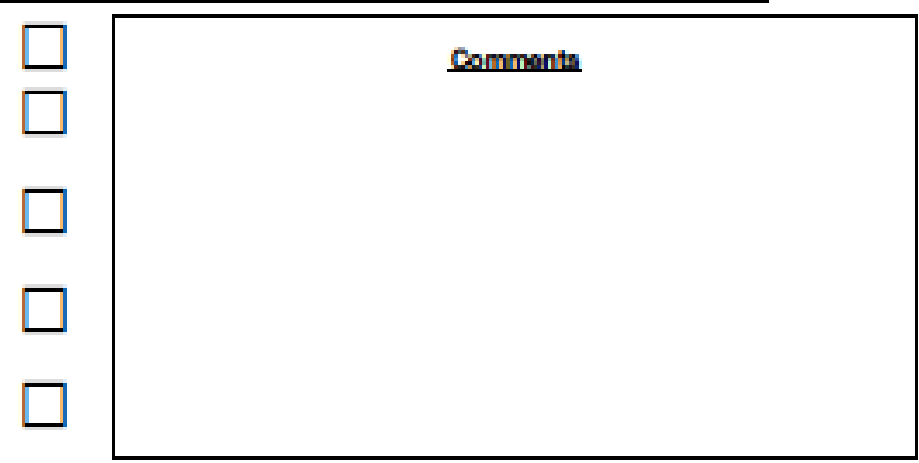

Tranatlons trrough varous levels of Revised Bloom's Taronomy to stimulate higher order thinking

Ubes ellective questioning strategles to stmulste higher order thinking reievont to the lesson

Ofers students mutpie ways to octain material besides tradtions lecture

Makes accommodatona for different learning styles

Provides clear and concles instructons

Connects acthifies to focus skilvobjectlve

Nlows participants to process gained knowledge

Regularty checks for students' understanding

Oters students more than one way to demonatrate Knowledgeiunderstanding

Uess creative assessment toola other than tradtong: quimes and test

Oters elective dosure to the lesson

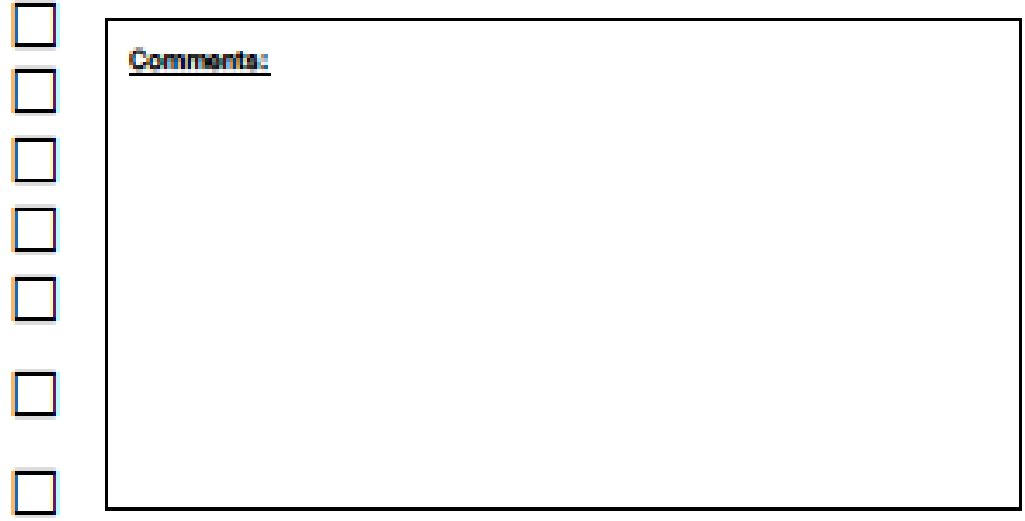

6. Eatabliahing High Expectations \& Engaging Studente

Stimulates students' Interests

Uaes age appropriate language

Facltates dlecuseion that flows throughout the group (not only child-to-faciltator but child to-chlid)

Documents student partipation and engages al chlidren

Assigns and monitors cooperatie group roies

Potates among groups and monitors activity

Creates a weicoming environment conductue to learning

Ensures that students gained knowledge from the dyy's lesson

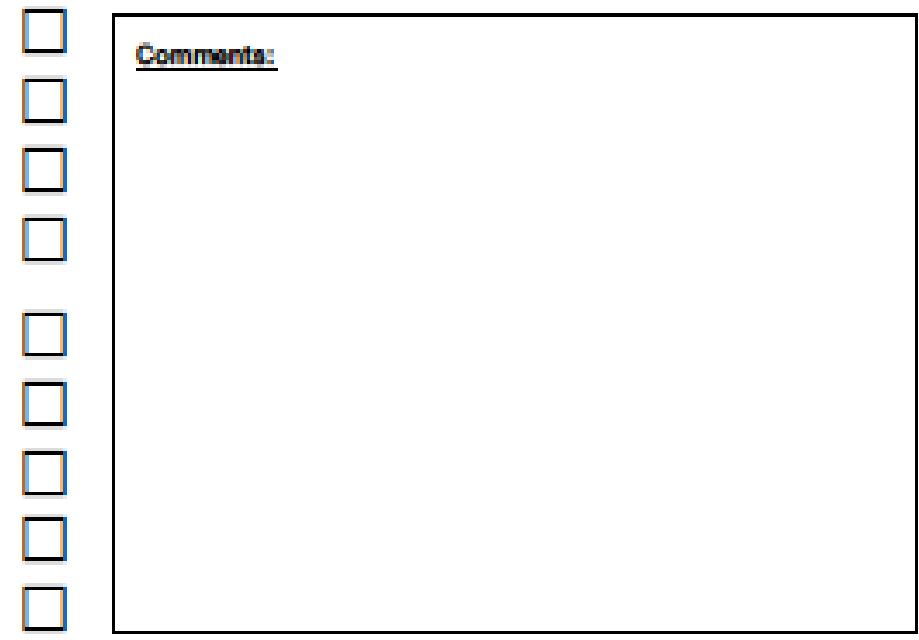




\section{REFERENCES}

Analoui, F. (1993). Training and transfer of learning. Lincoln, united Kingdom: Avebury.

Baxter, P., \& Jack, S. (2008). Qualitative case study methodology: Study design and implementation for novice researchers. The Qualitative Report, 13(4), 544-559.

Bell Jr, D. A. (1979). Brown v. board of education and the interest-convergence dilemma. Harv.L.Rev., 93, 518.

Bell, Y. R., \& Clark, T. R. (1998). Culturally relevant reading material as related to comprehension and recall in African American children. Journal of Black Psychology, 24(4), 455-475.

Brenner, M. E. (1998). Adding cognition to the formula for culturally relevant instruction in mathematics. Anthropology \& education quarterly, 29(2), 214-244.

Bruner, J. (1973). The relevance of education. WW Norton \& Company.

Brown, D. F. (2003). Urban teachers' use of culturally responsive management strategies. Theory into Practice, 42(4), 277-282.

Bryman, A. (2008). Social research methods ( $3^{\text {rd }}$ ed.). Oxford: Oxford University Press.

Caffarella, R. S. (2002). Planning programs for adult learners: A practical guide for educators, trainers, and staff developers. The Jossey-Bass higher and adult education series. ERIC.

Cahnmann, M. S., \& Remillard, J. T. (2002). What counts and how: Mathematics teaching in culturally, linguistically, and socioeconomically diverse urban settings. The Urban Review, 34(3), 179-204.

Children's Defense Fund (2014). Programs and campaigns. Retrieved from http://www.childrensdefense.org/programs-campaigns/freedom-schools/ 
Children's Defense Fund (2016). CDF Freedom Schools Program. Retrieved from http://www.childrensdefense.org/programs/freedomschools/

Closson, R. (2013). Racial and cultural factors and learning transfer. New Directions for Adult and Continuing Education, 2013(137), 61-69.

Conrad, N. K., Gong, Y., Sipp, L., \& Wright, L. (2004). Using text talk as a gateway to culturally responsive teaching. Early Childhood Education Journal, 31(3), 187-192.

Darling-Hammond, L., \& Bransford, J. (2007). Preparing teachers for a changing world: What teachers should learn and be able to do. John Wiley \& Sons.

Delpit, L. D. (2012). " Multiplication is for white people": Raising expectations for other people's children. The New Press: New York, NY.

Dunkerly, J. M. (2011). Reading the world in the word: The possibilities for literacy instruction framed within human rights education.

Fleishman, E. A. (1987). Foreword, in: S.M. Cormier \& J.D. Hagman (Eds.), Transfer of learning contemporary research and applications (pp.xi-xvii). San Diego, CA: Academic Press.

Flory, S. B., \& McCaughtry, N. (2011). Culturally relevant physical education in urban schools: Reflecting cultural knowledge. Research quarterly for exercise and sport, 82(1), 49-60.

Freire, P. (1972). Pedagogy of the Oppressed. 1968. Trans. Myra Bergman Ramos. New York: Herder.

Giroux, H. A. (1986). Radical pedagogy and the politics of student voice. Interchange, 17(1), 4869. 
Grabinger, S. (1996). Rich environments for active learning. In D. Jonassen (Ed.), Handbook of research for educational telecommunications and technology (pp. 665-692). New York: MacMillan.

Green, D. (2014). Freedom schools for the twenty-first century. Western Journal of Black Studies, 38(3), 163

Green, J. H. (2010). Who's the Boss? Culture and the Problem of Transfer. The International Journal of Learning, 17(6), 393-402.

Green, J. H. (2013). Transfer of learning and its ascendancy in higher education: a cultural critique. Teaching in Higher Education, 18(4), 365-376.

Groenke, S. L., Bennett, A., \& Hill, S. (2012). Not "if," but "why" and "how": What alreadymotivated black female readers can teach us about adolescent literacy instruction. CEDER Yearbook, 77-100.

Guha, S. (2006). Using mathematics strategies in early childhood education as a basis for culturally responsive teaching in India. International Journal of Early Years Education, 14(1), 15-34.

Hale, J. (2011). "The student as a force for social change": The Mississippi freedom schools and student engagement. The Journal of African American History, 96(3), 325-347.

Halpern, D. F., \& Hakel, M. D. (2003). Applying the science of learning to the university and beyond: Teaching for long-term retention and transfer. Change: The Magazine of Higher Learning, 35(4), 36-41.

Haskell, R. E. (2001). Transfer of learning: Cognition, instruction, and reasoning. San Diego, CA: Academic Press. 
Hefflin, B. R. (2002). Learning to develop culturally relevant pedagogy: A lesson about cornrowed lives. The Urban Review, 34(3), 231-250.

Herrington, A., Herrington, J., Hoban, G., \& Reid, D. (2009). Transfer of online professional learning to teachers' classroom practice. Journal of Interactive Learning Research, 20(2), 189.

Hickling-Hudson, A., \& Ahlquist, R. (2003). Contesting the curriculum in the schooling of Indigenous children in Australia and the United States: From Eurocentrism to culturally powerful pedagogies. Comparative Education Review, 47(1), 64-89.

Hollie, S. (2001). Acknowledging the language of African American students: Instructional strategies. The English Journal, 90(4), 54-59.

Horsford, S. D. (2011). Learning in a burning house: Educational inequality, ideology, and (dis) integration. Teachers College Press. 1234 Amsterdam Avenue, New York, NY 10027.

Howard, T. C. (2001a). Powerful Pedagogy for African American Students A Case of Four Teachers. Urban education, 36(2), 179-202.

Howard, T. C. (2001b). Telling their side of the story: African-American students' perceptions of culturally relevant teaching. The Urban Review,33(2), 131-149.

Jackson, T. O. (2009). Towards collective work and responsibility: Sources of support within a freedom school teacher community. Teaching and Teacher Education, 25(8), 1141-1149.

Jackson, T. O., \& Boutte, G. S. (2009). Liberation literature: Positive cultural messages in children's and young adult literature at freedom schools. Language Arts, 108-116.

Jackson, T. O., \& Howard, T. C. (2014). The continuing legacy of freedom schools as sites of possibility for equity and social justice for black students. Western Journal of Black Studies, $38(3)$ 
Jiménez, R. T. (1997). The Strategic Reading Abilities and Potential of Five Low-Literacy Latina/o Readers in Middle School. Reading Research Quarterly, 32(3), 224-243.

Jiménez, R. T., \& Gersten, R. (1999). Lessons and dilemmas derived from the literacy instruction of two Latina/o teachers. American Educational Research Journal, 36(2), 265301.

Korthagen, F., Loughran, J., \& Russell, T. (2006). Developing fundamental principles for teacher education programs and practices. Teaching and teacher education, 22(8), 1020-1041.

Ladson-Billings, G. (1995a). Toward a theory of culturally relevant pedagogy. American educational research journal, 32(3), 465-491.

Ladson-Billings, G. (1995b). Toward a theory of culturally relevant pedagogy. American educational research journal, 32(3), 465-491.

Ladson-Billings, G. J. (1999). Preparing teachers for diverse student populations: A critical race theory perspective. Review of research in education, 211-247.

Lee, C. D. (1995). A culturally based cognitive apprenticeship: Teaching African American high school students skills in literary interpretation. Reading research quarterly, 608-630.

Ligon, J. A., \& Chilcoat, G. W. (1999). " Helping to make democracy a living reality": The curriculum conference of the Mississippi freedom schools. Journal of Curriculum and Supervision, 15(1), 43-68.

Macaulay, C., \& Cree, V. E. (1999). Transfer of learning: Concept and process. Social Work Education, 18(2), 183-194.

McGill-Franzen, A., Lanford, C., \& Adams, E. (2002). Learning to be literate: A comparison of five urban early childhood programs. Journal of Educational Psychology, 94(3), 443. 
McLaren, P. (2010). Revolutionary critical pedagogy. InterActions: UCLA Journal of Education and Information Studies, 6(2).

Milner, H. R. (2010). What does teacher education have to do with teaching? Implications for diversity studies. Journal of Teacher Education, 61(1-2), 118-131.

Myers (1999). Monster. New York, NY: HarperCollins Publishers.

National Center for Education Statistics (2015). 2015 reading grades 4 and 8 assessment report cards: Summary data tables for national and state average scores and achievement level results. Retrieved from +http://www.nationsreportcard.gov/reading_math_2015/files/2015_Results_Appendix_R eading.pdf

Newell, G. E., \& Sweet, M. (1999). " Headed into more and more important things": Transforming a world literature curriculum. The English Journal,88(5), 38-44.

NVivo qualitative data analysis software; QSR International Pty Ltd. Version 10, 2010.

Payne, E., Laughter, J., Gilbert, B., Hoffman, A., \& Simpson, J. (2013). Culturally relevant pedagogy.

Perkins, D. N., \& Salomon, G. (1988). Teaching for transfer. Educational Leadership, 46(1), 2232.

Perkins, D. N., \& Salomon, G. (1989). Are cognitive skills context-bound?. Educational researcher, 18(1), 16-25.

Perkins, D. N., \& Salomon, G. (1992). Transfer of learning. International Encyclopedia of Education, 2

Perlstein, D. (1990). Teaching freedom: SNCC and the creation of the Mississippi freedom schools. History of Education Quarterly, , 297-324. 
Powell, R. (1997). Then the beauty emerges: A longitudinal case study of culturally relevant teaching. Teaching and Teacher Education, 13(5), 467-484.

Putnam, R. T., \& Borko, H. (2000). What do new views of knowledge and thinking have to say about research on teacher learning?. Educational researcher, 29(1), 4-15.

Roberson, L., Kulik, C. T., \& Pepper, M. B. (2009). Individual and environmental factors influencing the use of transfer strategies after diversity training. Group \& Organization Management, 34(1), 67-89.

Seidman, I. (2013). Interviewing as qualitative research: A guide for researchers in education and the social sciences. Teachers college press.

Sheets, R. H. (1995). From remedial to gifted: Effects of culturally centered pedagogy. Theory into practice, 34(3), 186-193.

Siffre, L. (1990). Something inside so strong. On So strong. China.

Smith, K. (2010). Fostering regimes of truth: understanding and reflecting on the Freedom School way. Pedagogy, Culture \& Society, 18(2), 191-209.

Stuart, D., \& Volk, D. (2002). Collaboration in a culturally responsive literacy pedagogy:

Educating teachers and Latino children. Reading, 36(3), 127-134.

Sturkey, W. (2010). "I want to become a part of history": Freedom summer, freedom schools, and the freedom news. Journal of African American History, 95(3), 348-368.

Tate, W. F. (1995). Returning to the root: A culturally relevant approach to mathematics pedagogy. Theory into practice, 34(3), 166-173.

Taylor, D. B., Lara-Cinisomo, S., \& Glover, C. (2013). Freedom School Partners Children's Defense Fund Freedom Schools@ Program Evaluation Report. Center for Adolescent Literacies at UNC Charlotte. 
Thorndike, E. L. (1901). The human nature club: An introduction to the study of mental life. Longmans, Green and Company.

Watson, M. (2014). Freedom schools then and now: A transformative approach to learning. Journal for Critical Education Policy Studies, 12(1)

Wlodkowski, R. J., \& Ginsberg, M. B. (1995). Diversity \& Motivation: Culturally Responsive Teaching. Jossey-Bass Higher and Adult Education Series. Jossey-Bass Education Series, Jossey-Bass Social and Behavioral Science Series. Jossey-Bass Inc., 350 Sansome St., San Francisco, CA 94104.

Yin, R. K. (2003). Case study research design and methods third edition. Applied Social Research Methods Series, 5

Zeichner, K. (2010). Rethinking the connections between campus courses and field experiences in college-and university-based teacher education. Journal of teacher education, 61(1-2), 89-99. 